EX P E R E N C I A

\title{
Estaciones de aprendizaje en un centro de Educación Especial
}

\section{Learning Stations in a Special Educational Needs (SEN)}

\author{
$\mathrm{M}^{\mathrm{a}}$ Dolors Signes i Monferrer*, Miquel Moreno Cardona*
}

Recibido: 6 de septiembre de 2020 Aceptado: 8 de diciembre de 2020 Publicado: 31 de enero de 2021

To cite this article: Signes, M. D., y Moreno. M. (2021). Estaciones de aprendizaje en un Centro de Educación Especial. Márgenes, Revista de Educación de la Universidad de Málaga, 2 (1), 148-174

DOI: https://doi.org/10.24310/mgnmar.v2i1.10164

\section{RESUMEN}

El proyecto de aula que explicamos a continuación es el resultado del trabajo en un centro público de educación especial de la ciudad de Castelló. La experiencia se ha llevado a cabo en un aula con 8 alumnos de la etapa de secundaria, y es fruto de las inquietudes, dudas, reflexiones y debates de dos maestros convencidos de que es posible acompañar los aprendizajes de otra manera, independientemente que sea en centro ordinario o en centro específico.

La base del proyecto la encontramos en una educación respetuosa e inclusiva, aplicada a través de la organización del trabajo en estaciones de aprendizaje.

Palabras clave: estaciones de aprendizaje; autodeterminación; inclusión; multinivel; autoevaluación; documentación

\section{ABSTRACT}

This classroom project is the result of the work in a state SEN in Castelló. The experience has taken place in a secondary school classroom with 8 students, and it stems from the inquisitiveness, doubts and reflections of two teachers who are convinced that it is possible to companion learning in a different way.

The project is based on a respectful and inclusive education approach, applied through learning stations work organization.

Keywords: learning stations; self determination; inclusion; multilevel; self assessment; documentation

\section{INTRODUCCIÓN Y CONTEXTUALIZACIÓN. ANTECEDENTES E HISTORIA}

Llegamos al centro de educación especial el curso 17-18, veníamos de trabajar en una UECIL y en otro centro específico por lo que ya teníamos una cierta experiencia como maestros de alumnado que requería grandes apoyos.

La idea de este proyecto surgió a partir de las inquietudes y de la ilusión de hacer las cosas de manera diferente para poder mejorar la vida de nuestro alumnado, proporcionarles nuevas herramientas útiles para relacionarse y formar parte de la sociedad dentro de las posibi-

"Ma Dolors Signes i Monferrer CPEE Castell Vell (España)

loleta14@yahoo.com

\footnotetext{
"*Miquel Moreno Cardona

CPEE Castell Vell (España)

miquel.mc6@gmail.com
} 
lidades de cada uno. Hay que decir que, como en todo proceso de cambio, hemos pasado por diferentes períodos y sin haber transitado estas diferentes etapas ahora no nos encontraríamos en este punto. Es fácil echar la vista atrás y ver que lo que hacíamos al principio no era lo que queríamos, pero en ese momento, acabados de aterrizar en el centro, nos sumamos a la manera de trabajar de la escuela y bien por desconocimiento, bien por la propia inercia, seguimos la línea metodológica del centro.

El primer curso tomamos conciencia de donde estábamos y de que lo que hacíamos no era demasiado útil ni significativo para nuestro alumnado. Sesiones magistrales con materiales mínimamente adaptados a cada uno, sesiones de audición y lenguaje individuales fuera del aula, ACIS como documentos obligatorios pero no de trabajo, etc. Queremos remarcar que el paso por este punto ha sido necesario para darnos cuenta de que teníamos que cambiar la manera de hacer las cosas. Sabíamos lo que no nos gustaba pero todavía no teníamos claro cómo hacerlo.

Al terminar el primer curso surgieron las primeras conclusiones: el camino que estábamos siguiendo no era el correcto. Por este motivo empezamos a preparar nuevos materiales para el siguiente curso mucho más manipulativos y visuales, lo que hizo que nos pudiéramos adaptar mejor a la realidad de cada alumno del aula. Empezamos a dar importancia a la autonomía y la toma de decisiones de nuestro alumnado, realizando también las sesiones de AL en el rincón de las letras dentro del aula de referencia. Aun así, durante todo este segundo curso continuamos reflexionando, leyendo y documentándonos para poder crear el proyecto de trabajo actual.

Ha sido este tercer curso escolar (19-20) cuando hemos podido poner en práctica las conclusiones y acciones surgidas del proceso de reflexión, tal como explicaremos a continuación. Sin embargo, lo que estamos haciendo en este momento no es lo que habíamos previsto. Inicialmente el proyecto englobaba las 4 aulas de secundaria, y a grandes rasgos consistía en trabajar por rincones aprovechando todos los apoyos y los diferentes espacios, y mezclando los alumnos según sus intereses. Como en la etapa de secundaria la mayoría de los maestros que hemos iniciado este curso son nuevos en el centro, el proceso vital de cada uno es muy diferente y estas reflexiones que nosotros ya nos habíamos hecho es necesario que cada uno las haga a su ritmo. De ahí que hayamos cambiado la idea inicial y modificado el proyecto.

Al mismo tiempo en el territorio valenciano ha habido un cambio normativo muy importante que nos reafirma en lo que hacemos y nos ofrece un marco legal propicio para encajar nuestra manera de entender la educación. Nuestra intención pedagógica va más allá de la propia normativa, pero entendemos que es un camino que debemos seguir para llegar a la verdadera calidad educativa, siempre con la inclusión y la calidad de vida como objetivos finales.

Primero se publicó el Decreto por el que se desarrollan los principios de equidad y de inclusión en el sistema educativo valenciano (Decreto 104/2018, de 27 de julio). El año siguiente, 2019, se publica la Orden por la que se regula la organización de la respuesta educativa para la inclusión del alumnado en los centros docentes sostenidos con fondos públicos del sistema educativo valenciano (Orden 20/2019, de 30 de abril).

A partir de este Decreto y de esta Orden y con las Resoluciones que las desarrollan se crea un marco educativo que potencia la inclusión. Este proceso ya se había iniciado años atrás, pero es a 


\section{E X P E R I E N C I A S}

partir de este momento cuando las escuelas empezamos a tomar conciencia de que la educación o es inclusiva, o no es educación.

De estos documentos es importante resaltar el nuevo papel que se nos otorga a los maestros de pedagogía terapéutica y de audición y lenguaje. Pasamos a ser personal especializado de apoyo a la inclusión, y obligatoriamente tenemos que cambiar nuestro papel dentro de la escuela, asumiendo que somos el motor del cambio.

Con estos elementos y basándonos en las 3 preguntas que hace Tomlinson (2001) para plantear la diversificación, hemos visto que:

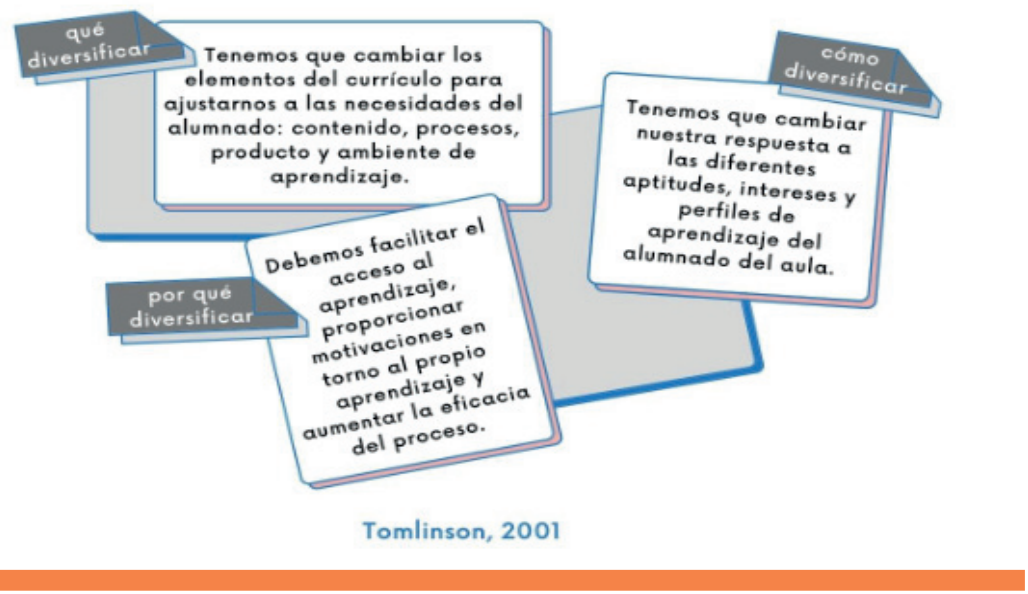

Imagen 1. Preguntas para plantear la diversificación. Tomlinson (2001)

\section{BASES TEÓRICAS. JUSTIFICACIÓN}

Vamos a hacer un breve repaso por lo que han sido nuestras guías en el desarrollo del proyecto. No pretende ser una explicación exhaustiva, pero nos parece importante tener presentes estos fundamentos que nos ayudan a entender el porqué de nuestra práctica docente.

\subsection{Modelo de calidad de vida}

Según Schalock y Verdugo (2007, p. 2) la calidad de vida se define como: "un estado deseado de bienestar personal que es multidimensional; tiene propiedades éticas ligadas a la cultura; tiene componentes objetivos y subjetivos; $y$ está influenciada por factores personales y ambientales".

El concepto de calidad de vida se puede aplicar a programas prácticos según una serie de principios (Schalock y Verdugo, 2007):

- Es multidimensional: abarca multitud de dimensiones y siempre tiene los mismos componentes para todas las personas, independientemente de la discapacidad que pueda tener una persona.

- Está influenciada por factores personales y ambientales, relacionados directamente con el contexto y con la propia persona. 
- Se mejora en autodeterminación, los recursos, el propósito de vida y el sentido de pertenencia. Dentro de este principio nos encontrábamos con las principales necesidades de nuestro alumnado, ya que nunca han sido acostumbrados a decidir, a tener responsabilidades, a formar parte de la sociedad de manera activa o tener objetivos a lo largo de su vida.

- Su aplicación debe basarse en la evidencia.

Los autores nos proponen 8 dimensiones de calidad de vida, a las que pretendemos atacar con la aplicación de este proyecto, teniéndolas como marco principal de referencia para programar todas las acciones a realizar con nuestro alumnado. Estas son:

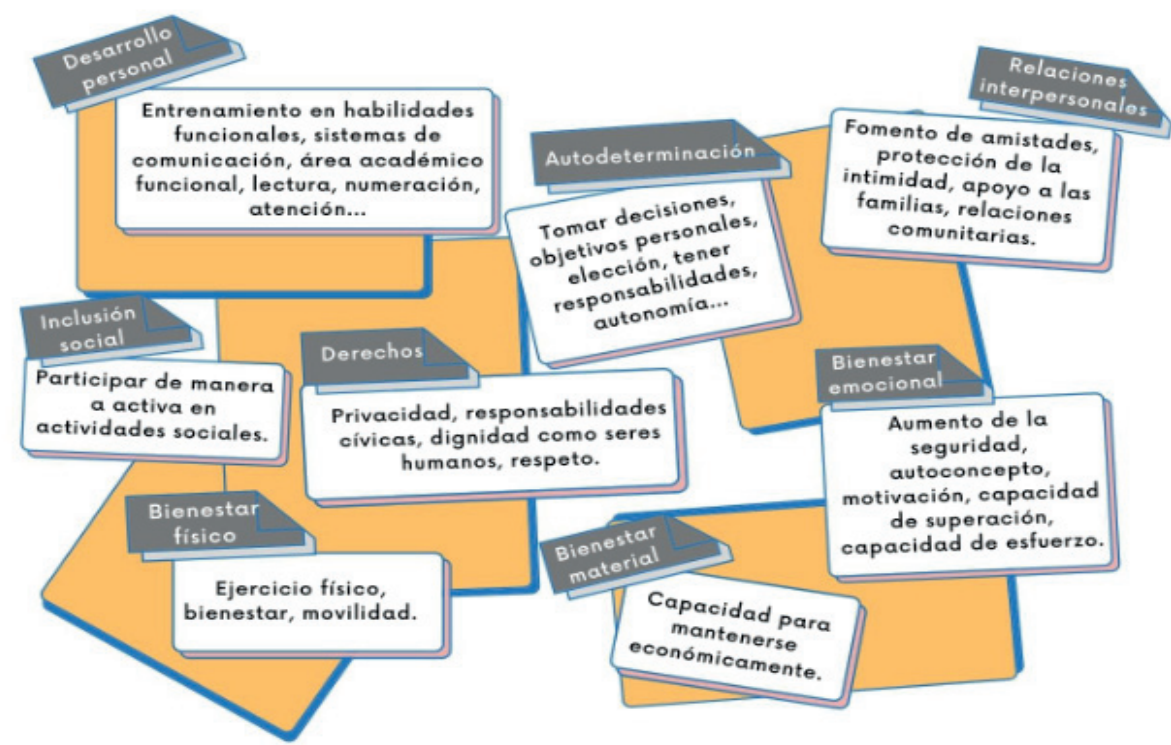

Dimensiones de calidad de vida. Schalock y Verdugo

Imagen 2. Dimensiones de calidad de vida. Schalock y Verdugo (2007)

\subsection{Planificación centrada en la persona}

La Planificación Centrada en la Persona sigue siendo el principal enfoque en el apoyo a personas con diferentes discapacidades, ya que ofrece estrategias basadas en valores y en el empoderamiento de las personas para ayudarlas a construir su propio proyecto de vida plena, de felicidad. El punto de partida de estos enfoques es el reconocimiento de la dignidad de cada persona, independientemente de las condiciones que acompañan su vida (Carratalá, Mata y Crespo, 2017)

Es una herramienta que nos permite apoyar a la persona a definir y vivir la vida que le gustaría tener para sentirse más feliz. Se basa en los siguientes valores (O’Brian, 1987):

1. La persona pertenece a su contexto social, por lo que debemos asegurar su presencia en el seno de su propia comunidad.

2. La amistad es uno de los valores más preciados de cualquier ser humano, por lo que hay que asegurar que la persona cuenta con una red de relaciones significativas. 
3. La persona es la protagonista de su vida, por lo que tenemos que respetar y potenciar sus elecciones en todo momento.

4. Nos basamos en el respeto hacia cada persona, en sus capacidades y en sus posibilidades de contribuir, por lo que potenciamos los roles sociales valorados.

5. Para conseguir sus sueños y disfrutar de su vida plena daremos apoyo al desarrollo de las competencias y habilidades necesarias para conseguirlo.

\subsection{Educación respetuosa}

El término engloba diferentes visiones o maneras de entender la educación: educación consciente (aware parenting), disciplina positiva, comunicación no violenta... Todas ellas tienen en común un cambio de paradigma, pasar de ver a los niños como seres inferiores, sin derechos y pasivos, a entender que son los protagonistas de su propia vida, y que nuestro papel es acompañar este proceso dejando que ellos asuman el protagonismo.

Siguiendo con este cambio de mirada, los niños y los jóvenes son seres activos, son sujetos y no objetos, no estamos formando a los ciudadanos del futuro porque ya son ciudadanos de pleno derecho del presente, de su presente.

Generalmente pedimos respeto a los niños y a los jóvenes hacia el adulto, pero el respeto debe ser mutuo y los adultos tenemos que dar ejemplo. Así, el respeto y la empatía deberían formar parte del día a día en las aulas, no debemos olvidar que nuestros alumnos son personas, con una historia propia de la que nosotros formamos parte pero no que nos pertenece. Si queremos respeto hacia nosotros, poder afirmar nuestra individualidad, nuestra originalidad y la elección de nuestro propio camino, ¿no tendremos que hacer lo mismo con el alumnado?

A través de la educación respetuosa ofrecemos seguridad física pero también, y sobre todo, emocional. Los jóvenes deben sentirse seguros, confiar en ellos mismos y en su entorno, y esto se consigue cuando los ayudamos a poner palabras a sus emociones ( $\mathrm{y}$ a las nuestras), cuando se sienten acompañados, no juzgados y escuchados, cuando favorecemos su autonomía y la comprensión del mundo que les rodea, cuando les ofrecemos límites claros que estructuran su ambiente, límites con sentido, razonados y justificados, no límites para castigar o para que escarmienten.

¿Qué implicaciones tiene educar desde el respeto?:

Una educación respetuosa exige un alto nivel de implicación porque hay que estar presentes, atentos, conectados con nosotros y con nuestros alumnos.

Implica un alto nivel de conciencia hacia nosotros mismos y hacia nuestros alumnos. Tenemos que saber qué hacemos y por qué lo hacemos, nosotros y ellos.

Pide disponer de un alto nivel de conocimiento de nuestras capacidades, nuestras necesidades, nuestras emociones... y de las suyas. 


\section{E X P E R I E N C I A S}

\subsection{Docencia compartida}

De acuerdo con Stainback (2001), la educación inclusiva es:

Un proceso por el que se ofrece a todos losniños, sin distinción de capacidad, raza o cualquier otra característica, la oportunidad de continuar siendo miembro de la clase ordinaria y de aprender de sus compañeros y junto con ellos, dentro del aula. (Stainback, 2001, p.18)

La Docencia Compartida, entendida como (pero no solo) la cooperación de dos maestros dentro del aula nos permite aplicar esta visión de la educación en el día a día de nuestras aulas.

Esto implica que todo el alumnado participe tanto como pueda del día a día de su aula, recibiendo los apoyos necesarios en el mismo entorno que el resto de los compañeros: el aula de referencia.

Los diferentes modelos de docencia compartida son:

- Dos docentes con liderazgo diferente

- Dos docentes con el mismo liderazgo que se distribuyen los agrupamientos de maneras diferentes:

- Enseñanza para estaciones o grupos rotativos: El aula se organiza a través de la división de los alumnos y de las tareas, se puede interactuar con los alumnos en pequeños grupos, observar cómo trabajan y poder conocer mejor las necesidades y los intereses.

- Enseñanza alternativa: El grupo se divide para dar un apoyo específico al alumnado según el objetivo y las necesidades.

- Enseñanza paralelo. El grupo se divide en dos subgrupos, cada uno con un maestro y ambos trabajan lo mismo.

- Dos docentes que trabajan en equipo con todo el grupo clase: Los dos maestros planifican, ejecutan y evalúan conjuntamente.

Como recoge Huguet (2006), estos son los cambios que provoca hacer el apoyo dentro del aula:

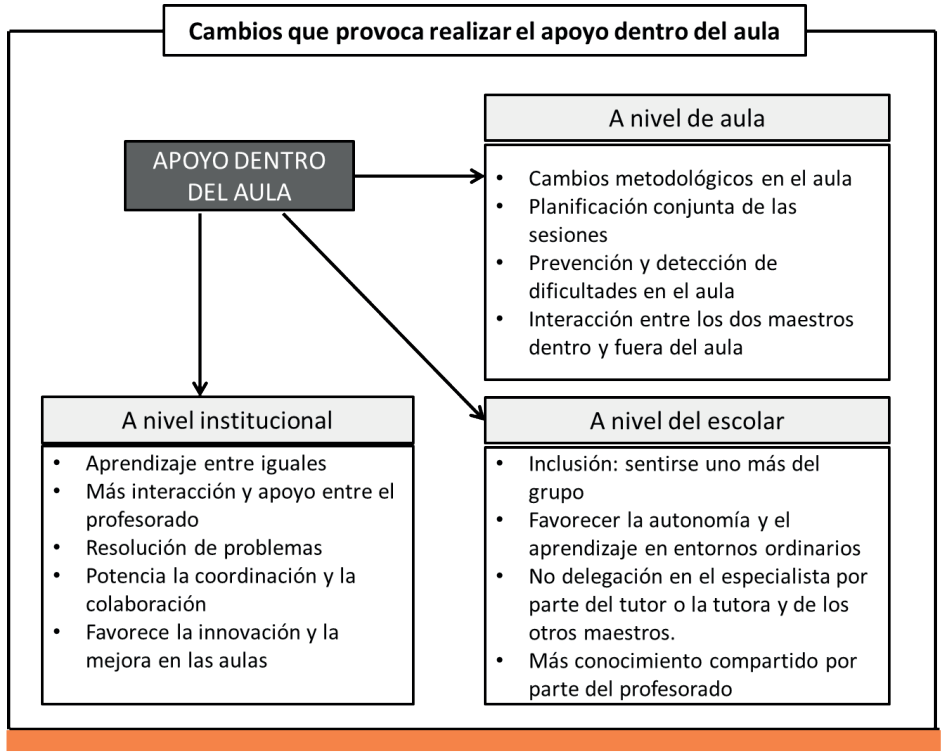

Imagen 3. Cambios que provoca realizar el apoyo dentro del aula Huguet (2006) 


\subsection{Programación multinivel}

La enseñanza multinivel (Schulz y Turnbull, 1984) se basa en la premisa de que una lección se ha de enseñar al conjunto de la clase. Es una aproximación a la planificación que asume la individualización, la flexibilidad y la inclusión de todos los alumnos, sin distinción de su nivel personal de habilidades. La enseñanza multinivel permite que el maestro planifique una lección para todos los alumnos, y así disminuye la necesidad de seguir programas diferentes, al tiempo que le posibilita la introducción de objetivos individuales en el contenido y en las estrategias educativas del aula Collicott (2002, p.1)

Según Arnaiz (2003), el diseño de actividades multinivel constituye otra manera de planificar la atención a la diversidad en el aula desde una perspectiva inclusiva, porque posibilita que cada alumno y alumna encuentre, respecto al acceso y desarrollo de un contenido, actividades acordes a su nivel de competencia curricular que le permita el progreso y la implicación de manera personalizada.

Para alcanzar la enseñanza multinivel, los maestros deberán tener en cuenta, siguiendo a Collicott (2002), los siguientes aspectos:

- Considerar los estilos de aprendizaje de los alumnos a la hora de planificar métodos de presentación.

- Hacerles participar en la lección mediante preguntas dirigidas a niveles diferentes de razonamiento (por ejemplo, utilizando taxonomías).

- Reconocer que deberán ajustarse las expectativas para con algunos alumnos.

- Permitir que los alumnos eligen el método que utilizarán para mostrar que entienden el concepto que se enseña.

- Aceptar que estos métodos diferentes tienen el mismo valor.

- Evaluar los alumnos en base a sus diferencias individuales.

De esta manera se promueve que todos los alumnos participan tanto como puedan, y los hace miembros de pleno derecho en el aula. Un aula en la que el maestro deja de dirigir y controlar, y en la que el alumnado asume que puede elegir y desarrollar su autonomía.

La programación multinivel se configura dentro de la pauta 8.2 del DUA: variar las demandas y los recursos para optimizar el desafío. Al mismo tiempo, responde al concepto de "ajustes razonables” que recoge la Convención sobre los derechos de las personas con discapacidad y protocolo facultativo de la ONU.

\subsection{Diseño Universal para el aprendizaje}

Este enfoque no es una metodología sino un marco teórico y práctico donde situar a la educación. Parte de la premisa de que hay una parte del alumnado que no llega a alcanzar los aprendizajes previstos en el currículo ya que estos están concebidos como si la mayoría del alumnado aprendie- 
ra de la misma manera. Y, en base a este alumnado, "se determinan los objetivos, se diseñan los medios y las tareas y se elaboran los materiales” Alba, Sánchez Serrano y Zubillaga (2011, p. 3). Por lo tanto, es el propio currículo el que dificulta o directamente impide que el alumnado acceda al aprendizaje.

Aunque el término DUA proviene de la arquitectura, en los años 90 el CAST (Centro para la tecnología especial aplicada) investigó, desarrollar y articular los principios y las características del Diseño Universal para el Aprendizaje, Estos principios son:

- Principio 1: Proporcionar múltiples formas de representación (hace referencia al qué del aprendizaje).

- Principio 2: Proporcionar múltiples medios de expresión (el cómo del aprendizaje).

- Principio 3: Proporcionar múltiples medios de compromiso (el porqué del aprendizaje).

Siguiendo estos 3 principios, el DUA plantea pautas que nos ayudarán a desarrollar el currículo y proporcionar apoyos para llegar a las necesidades de todo el alumnado.

\subsection{Pausas activas}

Las pausas activas tienen un papel clave dentro de nuestro proyecto, ya que para la distribución horaria del centro nos encontramos con grandes espacios de tiempo en el aula.

Siguiendo a Vaca (2006), las pausas activas consisten en actividades dentro del trabajo de aula de entre 5 y 10 minutos en las que la dinámica de la clase cambia para que el cuerpo y el movimiento tomen protagonismo.

Con ello se pretende conseguir una repercusión directa en apagar la fatiga escolar y en una mejora de la atención y el ambiente del aula, como si fuera una función de reinicio que aumenta la implicación y disposición hacia los siguientes procesos de enseñanza-aprendizaje.

Es importante destacar que las actividades propuestas no están pensadas como tiempo libre para hacer lo que cada uno quiera sin tener en cuenta a los compañeros y compañeras, sino que todos juntos tenemos que realizar la misma tarea o juego siguiendo unas normas y unos pasos determinados.

\subsection{Index for Inclusion. Barreras para el aprendizaje y la participación}

El Index for Inclusion de Booth y Aisncow es una herramienta esencial para "impulsar los procesos de cambio hacia una mayor inclusión educativa en los centros escolares, teniendo en cuenta los puntos de vista de los diferentes miembros de la comunidad educativa." Sandoval et al., (2002, p. 227)

Es una guía para evaluar y mejorar la educación inclusiva a través de materiales que permitan a los centros hacer un recorrido por sus prácticas. En él se habla de "barreras para el aprendizaje”, en lugar de alumnado con necesidades educativas especiales, ya que esta manera de etiquetar al alumnado puede generar expectativas más bajas por parte de los docentes. 
Esta herramienta aboga por un modelo social, frente al modelo centrado en la discapacidad y las dificultades de aprendizaje.

Cuando se aplica el Index se promueve la reflexión y la evaluación compartida de todas las dimensiones: cultura escolar, políticas escolares y prácticas escolares.

\subsection{Evaluación mediante rúbricas}

Como todo proyecto nos encontramos con una parte fundamental de evaluación. Esta nos sirve para tener en cuenta los aspectos a mejorar, para dar forma a futuras actividades planteadas y para cuantificar y valorar el progreso y evolución de nuestro alumnado.

Con las características de nuestro alumnado y teniendo en cuenta la manera de trabajar propuesta, la observación directa toma un papel fundamental y clave, ya que gran cantidad de nuestros objetivos tienen una vertiente actitudinal y personal muy importante. Es por ello que conjuntamente con la observación directa se nos hace imprescindible utilizar una herramienta capaz de cuantificar y trasladar esta observación en una escala evaluable.

Según Díaz Barriga (2005), las rúbricas son guías o escalas de evaluación donde se establecen niveles progresivos de dominio relativos al desarrollo que una persona muestra respecto a un proceso o producción determinada.

Bilbatua y Egizabal (2010), describen las rúbricas como una herramienta versátil que se puede utilizar de manera muy diferente para evaluar y para tutorizar el trabajo del alumnado.

En nuestro caso la rúbrica muestra qué esperamos de nuestros alumnos respecto a cualquiera de los objetivos planificados, sobre todo en autonomía y decisión tal y como explicaremos en la segunda parte del artículo. Teniendo en cuenta las características y necesidades de nuestro alumnado, somos los docentes los que elaboramos la rúbrica de evaluación y transmitimos verbalmente — a quien tenga la capacidad para comprenderlo- qué esperamos de ellos y hasta dónde pueden llegar.

\subsection{Estaciones de aprendizaje}

Como se recoge en el libro "El aula diversificada", "las estaciones son diferentes puntos dentro de la clase, donde los estudiantes trabajan simultáneamente realizando distintas tareas” (Tomlinson, 2001, p. 115).

Nos permite abordar diferentes aspectos que consideramos importantes:

- Todos los alumnos trabajan al mismo tiempo.

- Se forman agrupaciones flexibles en cada sesión de trabajo.

- Hay un equilibrio entre lo que eligen los docentes y lo que elige el alumnado.

- Las tareas varían de un día a otro. 


\section{E X P E R I E N C I A S}

- No todos tienen que pasar por todos los espacios cada día.

- Las tareas varían de un alumno a otro.

- Hay actividades individuales, por parejas, de pequeño grupo y de gran grupo.

- Se fomenta la autonomía en el trabajo.

- Se fomenta la libre elección y la autodeterminación del alumnado.

- El docente pierde relevancia para poner al alumno en el centro del proceso (cambia el foco de atención).

\subsection{Documentación del proceso}

Asumimos la importancia de la documentación que otorga la pedagogía de Reggio Emilia ya que sin ella los procesos pedagógicos no se consolidarían ya que nos sirve para la reflexión y la construcción pedagógica.

Es por ello que uno de los pilares básicos de nuestro proyecto es la documentación, sobre todo por los objetivos que perseguimos con ella y la manera de hacerlo.

El proceso de documentación tiene dos vertientes: la interior y la exterior. Por un lado, la vertiente interior nos da poder para trabajar la autoevaluación, valorar la evolución personal y tener conciencia de la evolución colectiva. Por otra parte, nos encontramos con una vertiente exterior, capaz de hacer visible el trabajo de aula en el exterior y trasladarlo a las familias o a los compañeros del centro.

Las principales características de la documentación del proyecto son:

- Sencillez

- Visual

- Práctica

- Adaptada

- Reflexiva

Como no podía ser de otro modo, la actividad de documentación está adaptada a las características y necesidades de cada uno de nuestros alumnos, pero sobre todo queremos hacer énfasis en la parte reflexiva y de autoevaluación.

\section{PLANIFICACIÓN}

Es la base de todo el proyecto. Sin planificación y programación nada de esto sería posible. Este proyecto nos permite prestar mucha atención a decidir cuáles son las actividades programadas, pero sobre todo para qué las proponemos. Nos planteamos siempre el porqué de cada actividad, ya sea de centro o de aula, por muy insignificante que pueda parecer. Por ejemplo, tomando 
como ejemplo la celebración del día de la Paz, no es lo mismo planificar una actividad que está en el calendario y que nos viene dada desde fuera y con poco tiempo de trabajo, en la que se busca sobre todo el resultado, la foto, que plantear abordar el significado de la Paz, entenderla como la ausencia de conflictos y dedicar tiempo y recursos personales, temporales y materiales para acompañar a los alumnos en la profundización en este concepto. Si tenemos claro el porqué de la actividad evitaremos que afloren nuestras frustraciones, los alumnos entenderán el sentido de la actividad y es probable que el aprendizaje subyacente sea significativo (vamos a hacer el cartel más bonito que podamos para sentirnos orgullosos de nuestro trabajo o, en cambio, vamos a analizar las situaciones de conflicto de hoy y vamos a ver cómo nos sentimos).

\subsection{Planificación personal}

Cada centro de educación especial organiza los recursos personales en función del proyecto educativo de centro y ajustándose a las necesidades detectadas. En nuestro caso, cada aula tiene un tutor de referencia y un educador. Las maestras de audición y lenguaje atienden al alumnado de dos o más clases, entre las que reparte su tiempo (habitualmente sacando al alumnado fuera del aula). En ocasiones también entra otra maestra de pedagogía terapéutica que realiza apoyos de manera puntual.

El cambio más significativo que hemos introducido en lo que respecta al personal ha sido que la maestra de $\mathrm{AL}$ permanece dentro del aula todas las horas que están asignadas a los alumnos de esa aula, por lo que estamos la mayor parte de la jornada los tres profesionales compartiendo el mismo espacio. Además, hay otros docentes que también participan en la vida de aula, como el maestro de educación física, de música o de religión, así como los apoyos puntuales. Aunque el grueso del proyecto lo desarrollamos los 3 profesionales que pasamos más tiempo dentro, cualquier persona que entre en clase sigue la estructura de aula. De esta manera, cuando otro profesional del centro entra en el aula asume un rol activo y no tiene que esperar las directrices del tutor para saber qué tiene que hacer.

\subsection{Planificación temporal}

Entendemos la planificación desde una doble vertiente:

- La que afecta a las estructuras y dinámicas de aula.

- La que se refiere a los aprendizajes que queremos fomentar.

En la planificación de las estructuras y las dinámicas de aula, utilizamos todas las franjas horarias en las que no tenemos especialistas o actividades de centro o etapa programadas para llevar a cabo el trabajo planificado. Se desdibujan de esta manera las franjas horarias, las áreas académicas o curriculares, los compartimentos estancos y aparece un hilo conductor que guía el día a día. 
En la tabla 1 se muestra el horario del aula que se nos facilitó a principio de curso, en el que se recogía una petición que hicimos el curso anterior. Como ya hemos comentado, inicialmente la idea era juntar a todo el alumnado de la etapa de secundaria para realizar rincones de trabajo usando los diferentes espacios (aulas, pasillos, taller de cocina...). Por ello la franja de 11:30 a 12:15 se organizó sin ningún especialista para que las 4 aulas pudiéramos coincidir y plantear las diferentes agrupaciones.

Tabla 1. Horario de aula

\begin{tabular}{|c|c|c|c|c|c|}
\hline HORA & LUNES & MARTES & MIÉRCOLES & JUEVES & VIERNES \\
\hline 10:00 - 11:00 & Educación física & $\begin{array}{l}\text { Académico } \\
\text { funcional }\end{array}$ & $\begin{array}{l}\text { Académico } \\
\text { funcional }\end{array}$ & $\begin{array}{l}\text { Académico } \\
\text { funcional }\end{array}$ & Educación física \\
\hline $11: 00-11: 30$ & Patio & Patio & Patio & Patio & Patio \\
\hline $11: 30-12: 15$ & Académico funcional & Religión / Valores & $\begin{array}{l}\text { Académico } \\
\text { funcional }\end{array}$ & $\begin{array}{l}\text { Académico } \\
\text { funcional }\end{array}$ & $\begin{array}{l}\text { Académico } \\
\text { funcional }\end{array}$ \\
\hline $12: 15-13: 00$ & Académico funcional & $\begin{array}{l}\text { Académico } \\
\text { funcional }\end{array}$ & $\begin{array}{l}\text { Académico } \\
\text { funcional }\end{array}$ & $\begin{array}{l}\text { Académico } \\
\text { funcional }\end{array}$ & $\begin{array}{l}\text { Académico } \\
\text { funcional }\end{array}$ \\
\hline $13: 00-14: 30$ & Comida & Comida & Comida & Comida & Comida \\
\hline $14: 30-15: 30$ & Académico funcional & $\begin{array}{c}\text { Académico fun- } \\
\text { cional }\end{array}$ & $\begin{array}{l}\text { Académico } \\
\text { funcional }\end{array}$ & $\begin{array}{l}\text { Académico } \\
\text { funcional }\end{array}$ & Talleres \\
\hline $15: 30-16: 30$ & Académico funcional & Música & $\begin{array}{l}\text { Académico } \\
\text { funcional }\end{array}$ & Música & Talleres \\
\hline
\end{tabular}

El día a día en el aula se estructura de la siguiente manera: el alumnado llega al centro a las 10:00h, momento en el que entramos en el aula y empezamos con las rutinas del día: dejar la agenda en su sitio para que la podamos leer, sacar el almuerzo y ponerlo en su sitio, bajar las sillas de las mesas, dejar las chaquetas, etc. Una vez han realizado estas tareas empezamos con el trabajo por estaciones de aprendizaje (que detallaremos más adelante).

Respecto a la planificación del propio trabajo no establecemos tiempos sino propuestas de trabajo multiniveladas y personalizadas, de manera que respetamos los ritmos de aprendizaje de cada uno de nuestros alumnos, acompañándolos pero sin forzarlos o urgirlos.

Por otro lado, según tenemos marcado en el horario los momentos para planificar qué va a hacer cada alumno se reducen a una hora de coordinación semanal. Como es obvio, ese tiempo no es suficiente así que aprovechamos cualquier momento dentro del aula para realizar comentarios, anotaciones, propuestas..., que quedan recogidas en la hoja de programación de cada alumno. También usamos la hora de la comida, del almuerzo, momentos de patio, el café, de camino a casa..., (aunque este tiempo debería estar recogido dentro de nuestro horario porque es la base de nuestro posterior trabajo, al final sacamos el tiempo de debajo de las piedras). 


\subsection{Planificación material}

Para desarrollar el proyecto los materiales han sido clave. Hemos preparado actividades, materiales, retos, tareas, juegos... suficientes para dotar de contenido los espacios. Esta tarea se desarrolla a lo largo de todo el curso de manera continuada: en la medida en que los alumnos progresan en las tareas que les ofrecemos debemos ir elaborando nuevos materiales, en ocasiones guiándonos por sus intereses, otras veces para profundizar en aspectos que no han quedado claros o que consideramos que hay que enriquecer.

En cada sesión de evaluación hemos ido revisando y planificando nuevos materiales, así el alumnado siempre tiene a su disposición variedad y alternativas para elegir. De esta manera permanentemente pueden llevar a la práctica el principio de autodeterminación, el hecho de poder elegir. Siempre que nos es posible elaboramos la misma actividad con diferentes niveles de complejidad para dar respuesta a los procesos cognitivos que ponen en marcha cada uno de los alumnos.

\section{DESCRIPCIÓN DE LA EXPERIENCIA}

\subsection{Programación unificada}

Todo proyecto parte de una programación y planificación ajustadas. En este caso nuestra programación está unificada y la hemos realizado en equipo docente.

Tal como establece la normativa y el proyecto educativo del centro, todos los alumnos de nuestra aula siguen una programación personalizada a partir de las adaptaciones curriculares individuales significativas (ACIS). Entendemos por ACIS:

\footnotetext{
"Una medida curricular extraordinaria de nivel IV dirigida al alumnado con necesidades educativas especiales que cursa la enseñanza obligatoria y presenta un desarrollo competencial, debidamente valorado con los instrumentos adecuados, inferior a dos o más cursos, tomando como referencia las competencias establecidas en el currículum ordinario oficial correspondiente al nivel en que se encuentra escolarizado.” (Orden 20/2019, de 30 de abril)
}

Entendemos que el concepto de adaptación curricular no se ajusta al modelo de educación inclusiva en el que creemos, puesto que si partiéramos de una planificación multinivelada ya nos estaríamos adaptando al nivel de cada uno de nuestros alumnos. En cualquier caso, es lo que se nos exige al inicio de curso y nosotros lo asumimos como el papeleo necesario para poder desarrollar nuestra labor. Otra cosa es la importancia que le otorguemos a dicho papeleo.

Antes de empezar el curso establecimos cuál sería el documento base para elaborarlas ya que así se podría tener una continuidad en el futuro. Existe una cierta controversia en torno al currículo que debemos seguir en los centros de educación especial. Nosotros consideramos que el currículo debería ser único, válido para todo el alumnado de la misma etapa, independientemente de la modalidad de escolarización que cada persona tenga, y sin perder de vista este criterio hemos realizado nuestra programación. 
Si tenemos en cuenta la edad cronológica deberíamos centrarnos en el Documento Puente y el Decreto de Secundaria, pero estos no nos serían funcionales ya que los criterios de evaluación e indicadores de éxito quedan muy descontextualizados respecto a las necesidades de nuestro alumnado. Por este motivo decidimos utilizar el Documento Puente y el Decreto 108/2014 de 4 de julio, por el que establece el currículo y despliega la ordenación general de la Educación Primaria en la Comunidad Valenciana.

Hay que remarcar que con la utilización de este documento todavía nos encontramos con ciertos criterios de evaluación de nivel muy avanzado para nuestro alumnado, por lo que tenemos que secuenciar algunos de los indicadores para poder llegar a alcanzar el criterio de evaluación propuesto. A continuación, se muestran dos ejemplos:

1. Este primer caso hace referencia a un criterio de evaluación la alumna puede trabajar y alcanzar tal como está expresado en el documento puente. No necesita ningún tipo de secuenciación ya que esta alumna en concreto puede superarlo sin necesidad de realizar ajustes.

Tabla 2. Ejemplo de programación 1

\begin{tabular}{|c|c|c|c|c|c|}
\hline \multicolumn{6}{|c|}{ LENGUA } \\
\hline \multicolumn{6}{|c|}{ ÁREA: ACADÉMICO-FUNCIONAL } \\
\hline \multicolumn{6}{|c|}{ BLOQUE 2: COMUNICACIÓN ESCRITA. LEER } \\
\hline \multirow[t]{2}{*}{ CONTENIDOS } & \multirow[t]{2}{*}{ CRITERIOS DE EVALUACIÓN } & \multirow[t]{2}{*}{ INDICADORES DE ÉXITO } & \multicolumn{3}{|c|}{ NIVEL LOGRO } \\
\hline & & & 1 & 2 & 3 \\
\hline $\begin{array}{l}\text { Uso dirigido de les TIC } \\
\text { para obtener informa- } \\
\text { ción, haciendo uso de } \\
\text { aplicaciones de acuer- } \\
\text { do a su edad. }\end{array}$ & $\begin{array}{l}\text { 2n.CLL.BL2.3 Leer en medios } \\
\text { digitales para buscar y selec- } \\
\text { cionar de forma guiada infor- } \\
\text { mación de fuentes pre-selec- } \\
\text { cionadas y utilizarla en las ta- } \\
\text { reas de aprendizaje. }\end{array}$ & $\begin{array}{l}\text { 2n.CLL.BL2.3 Busca y selec- } \\
\text { ciona información de fuen- } \\
\text { tes pre-seleccionadas, en } \\
\text { medios digitales y de forma } \\
\text { guiada, para utilizarla en ta- } \\
\text { reas de aprendizaje. }\end{array}$ & & & \\
\hline
\end{tabular}

2. En este segundo caso nos encontramos un criterio de evaluación muy elevado para las características de la misma alumna, pero en el Decreto no disponemos de un nivel más bajo (el criterio corresponde a $1^{\circ}$ de primaria), por lo que secuenciaremos una serie de pasos para alcanzar el criterio de evaluación marcado, tal y como se puede ver en la siguiente tabla destacado con otro color. En este caso en concreto debemos elaborar material y actividades para empezar a trabajar los números de una cifra para posteriormente pasar a los números de dos cifras, ya que la alumna no tiene interiorizados los pasos o conocimientos previos para poder trabajar el criterio de evaluación marcado en el Decreto: 


\section{E X P E R I E N C I A S}

Tabla 3. Ejemplo de programación 2

MATEMÁTICAS

ÁREA: ACADÉMICO-FUNCIONAL

\begin{tabular}{|c|c|c|c|c|c|}
\hline \multicolumn{6}{|c|}{ BLOQUE 2} \\
\hline \multirow[t]{2}{*}{ CONTENIDOS } & \multirow{2}{*}{$\begin{array}{l}\text { CRITERIOS DE } \\
\text { EVALUACIÓN }\end{array}$} & \multirow[t]{2}{*}{ INDICADORES DE ÉXITO } & \multicolumn{3}{|c|}{ NIVEL LOGRO } \\
\hline & & & 1 & 2 & 3 \\
\hline $\begin{array}{l}\text { Nombre y grafía de los } \\
\text { números. } \\
\text { Orden numérico de los } \\
\text { números. Aproxima- } \\
\text { ción a las nociones de } \\
\text { mayor que, menor que, } \\
\text { igual que y a su repre- } \\
\text { sentación. } \\
\text { Identificación del valor } \\
\text { de las distintas mo- } \\
\text { nedas en relación con } \\
\text { precios de artículos co- } \\
\text { tidianos. }\end{array}$ & $\begin{array}{l}\text { 1rMAT.BL2.1 Leery } \\
\text { escribir el valor de } \\
\text { números naturales } \\
\text { hasta dos cifras en } \\
\text { situaciones de ca- } \\
\text { rácter numérico de } \\
\text { aula y personales } \\
\text { como edades; tallas; } \\
\text { estaturas, la lista; el } \\
\text { orden en las tareas; } \\
\text { juegos con la inten- } \\
\text { ción de medir, con- } \\
\text { tar, ordenar o com- } \\
\text { parar los números } \\
\text { utilizando monedas, } \\
\text { palillos, gomets... }\end{array}$ & $\begin{array}{l}\text { 1rMAT.BL2.1.1 Lee y escribe el valor } \\
\text { de números naturales hasta dos ci- } \\
\text { fras en situaciones de carácter nu- } \\
\text { mérico de aula y personales como } \\
\text { edades; tallas; estaturas, la lista; el } \\
\text { orden en las tareas; juegos con la } \\
\text { intención de medir, contar, ordenar } \\
\text { o comparar los números utilizando } \\
\text { monedas, palillos, gomets... } \\
\text {-Identifica los números del } 1 \text { al } 10 \\
\text {-Escribe los números del } 1 \text { al } 10 \\
\text {-Asocia número y cantidad (1 al 10) } \\
\text {-Asocia número y cantidad con las } \\
\text { barras rojas y azules y con núme- } \\
\text { ros de lija. } \\
\text {-Asocia número y cantidad con los } \\
\text { contadores. } \\
\text {-Asocia número y cantidad con las } \\
\text { regletas de colores. }\end{array}$ & & & \\
\hline
\end{tabular}

Estos son dos ejemplos de cómo se programan los criterios de evaluación de manera personalizada para cada uno de nuestros alumnos en las áreas de matemáticas y lengua. Esta programación, aunque inicialmente la hacemos por separado (el PT hace matemáticas, la AL hace lengua), en un segundo momento las compartimos y las comentamos, porque no concebimos el aprendizaje como compartimentos estancos, sino que las diferentes materias son parte de un todo. Por ejemplo, no se puede hacer conteo de palabras necesario para la conciencia fonológica si no sabemos cuántos elementos es capaz de contar el alumno, y viceversa, deberemos plantear los problemas matemáticos en función del nivel de comprensión oral o escrita de una alumna. Incluso, deberemos saber la capacidad de su memoria de trabajo para planificar actividades de ambas áreas.

Por último, también realizamos la programación de la asignatura de valores cívicos y sociales, pero esta la desarrollamos de manera transversal, está presente en las actividades del día a día independientemente del rincón o estación de aprendizaje escogido, de si la actividad es dentro del colegio o de si hay una salida programada. 


\section{E X P E R I E N C I A S}

Todos estos documentos se trasladan a la hoja de programación quincenal, que es nuestra herramienta de trabajo diaria en el aula.

Esta hoja es la concreción de la programación de cada alumno. Seleccionamos de la ACIS cuáles son los indicadores que queremos trabajar y los desarrollamos con actividades personalizadas. A lo largo de dos semanas hacemos las anotaciones pertinentes teniendo en cuenta si la actividad se ajusta a lo que queremos trabajar o a su nivel, si le motiva, qué tipo de apoyo necesita (si requiere ayuda visual, supervisión de otra persona, modelos ya elaborados para copiarlos...). Además, en función de esta información hacemos propuestas para introducir nuevos aspectos o de pasar al siguiente nivel en la próxima quincena, con lo que hacemos una evaluación diaria de lo que pasa dentro del aula con cada alumno y de la interacción entre todos las personas del aula, tanto compañeros como equipo educativo.

Es importante remarcar que vamos anotando todos los espacios por los que pasan, con lo que tenemos un seguimiento del trabajo y nos aseguramos de que han pasado por todas las estaciones por igual. En caso de que algún alumno haya estado evitando durante un par de días un espacio nos planteamos las posibles causas y si podemos, las analizamos con ellos. Puede deberse a que prefiere trabajar en grupo y no coincidía con nadie en ese espacio, puede ser que la propuesta que tenía en dicho espacio no le resultaba motivadora, que tenía una actividad sin terminar en otro rincón...

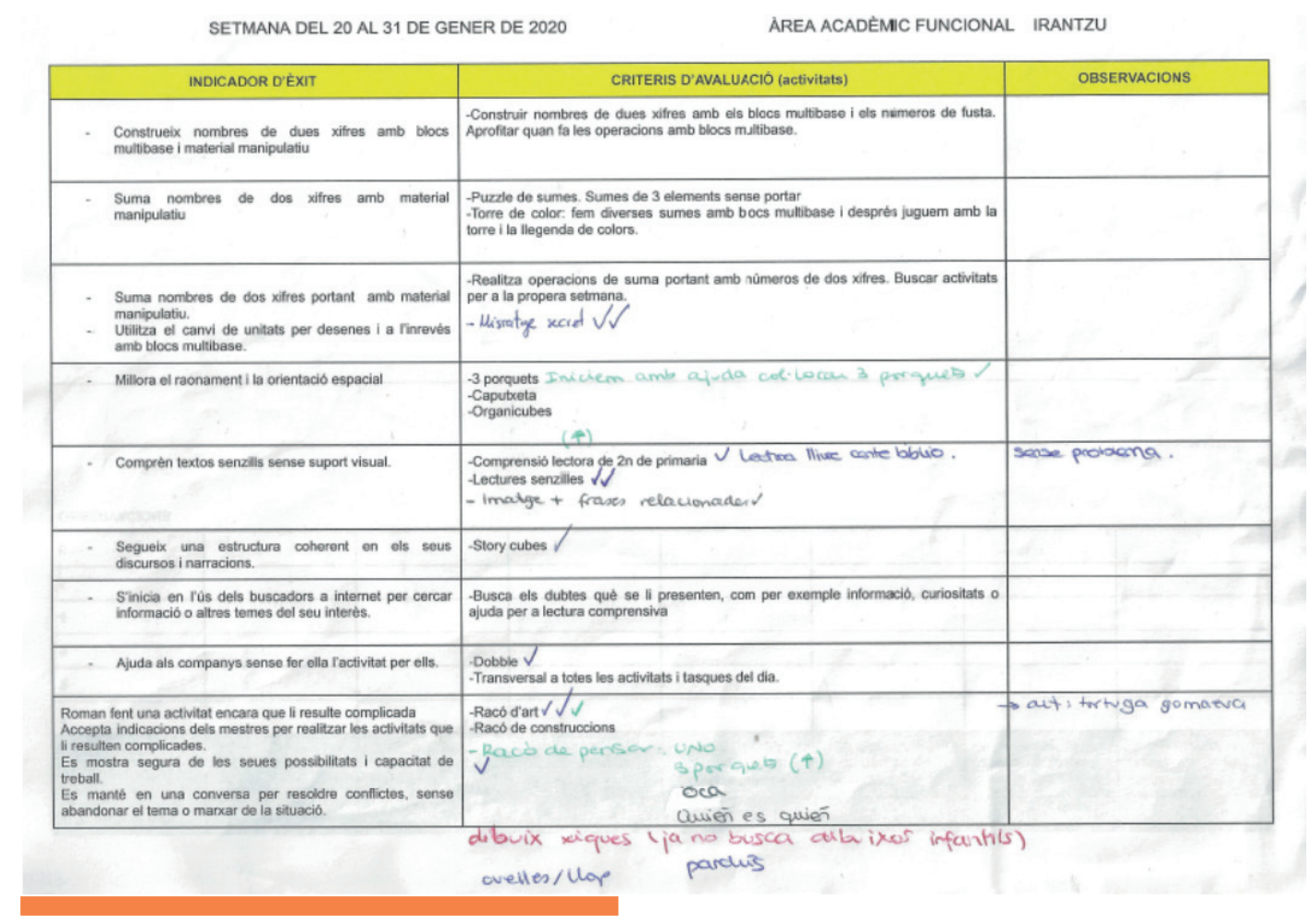

Imagen 4. Hoja de programación quincenal 
EX P E R I E N C I S

\subsection{Trabajo en las estaciones de aprendizaje}

Las estaciones de aprendizaje nos permiten que cada alumno pueda planificar qué actividad quiere hacer en cada momento. Es en este momento cuando eligen qué tarea quieren hacer, cogen la hoja de programación individual que siempre tienen a su alcance (ellos son los encargados de llevar al espacio que han elegido), y se preparan el espacio: bien mueven el mobiliario para crear una zona adecuada para trabajar, bien van a buscar los juegos o materiales que necesitan, bien sientan y esperan a que les demos el trabajo (según el alumno y la actividad elegida).

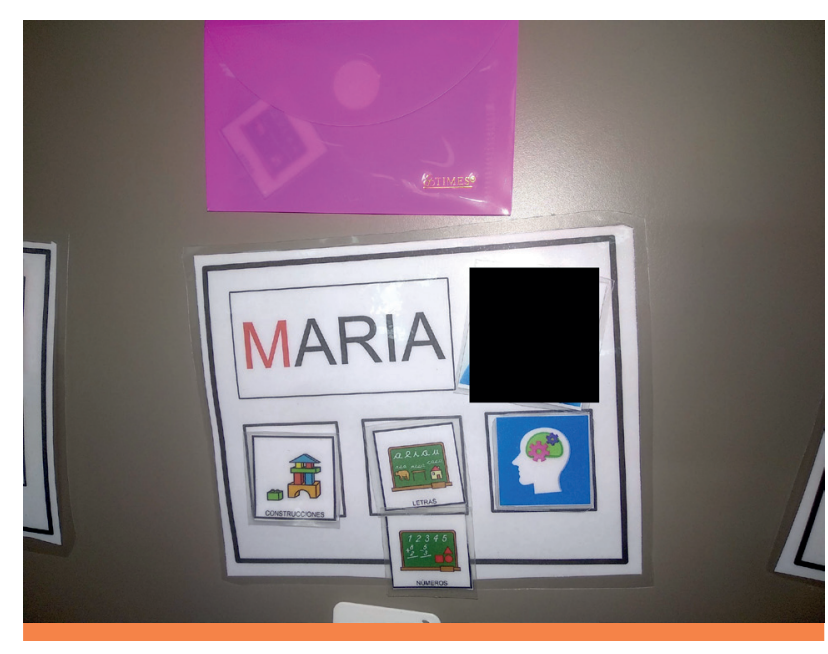

Imagen 5. Pictogramas de los rincones y estaciones de aprendizaje

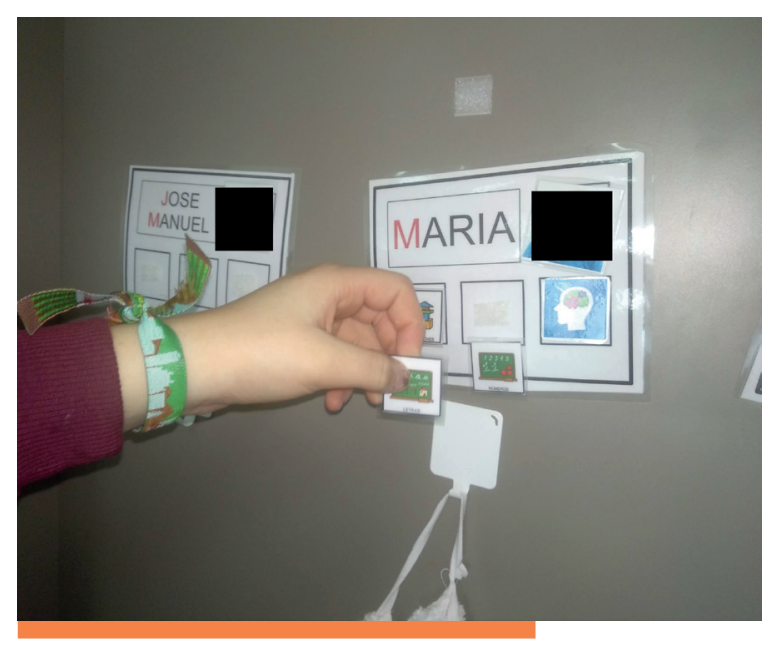

Imagen 6. Elección de la actividad

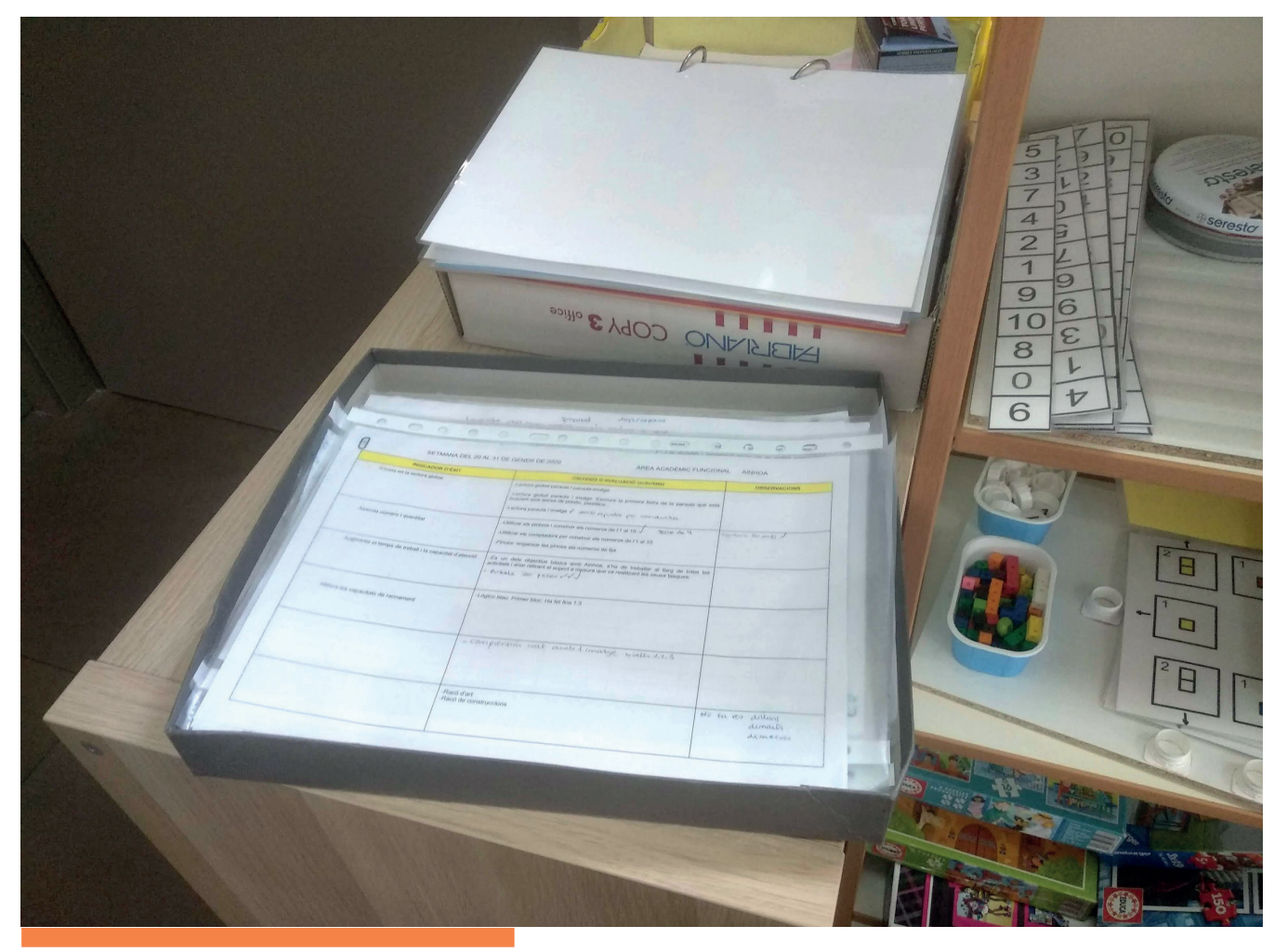

Imagen 7. Hoja de programación 
margenes

EX P E R I E N C I A S

Pueden escoger entre cuatro tipos de estación: números, letras, arte y juegos de pensar (juegos de lógica y razonamiento).

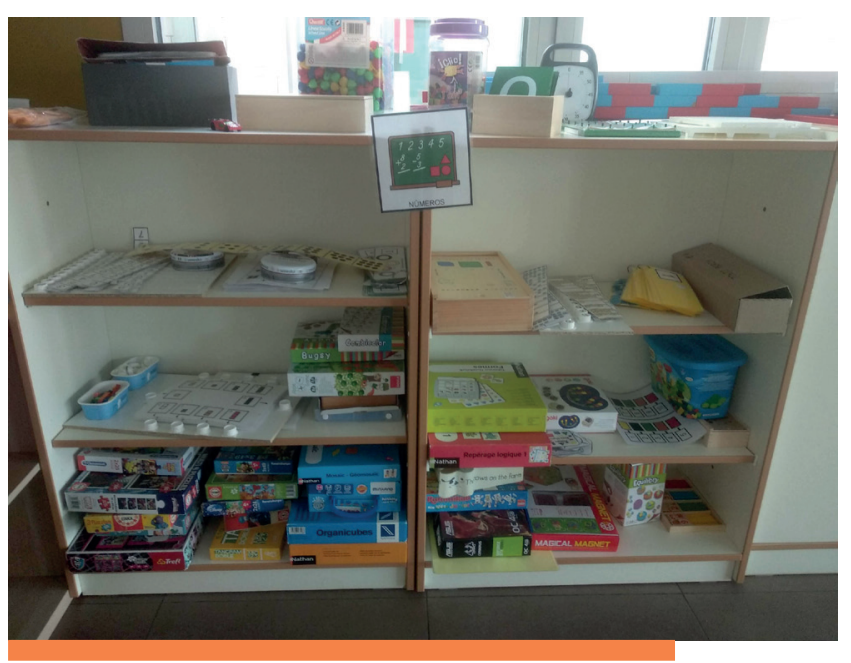

Imagen 8. Material de la estación de números

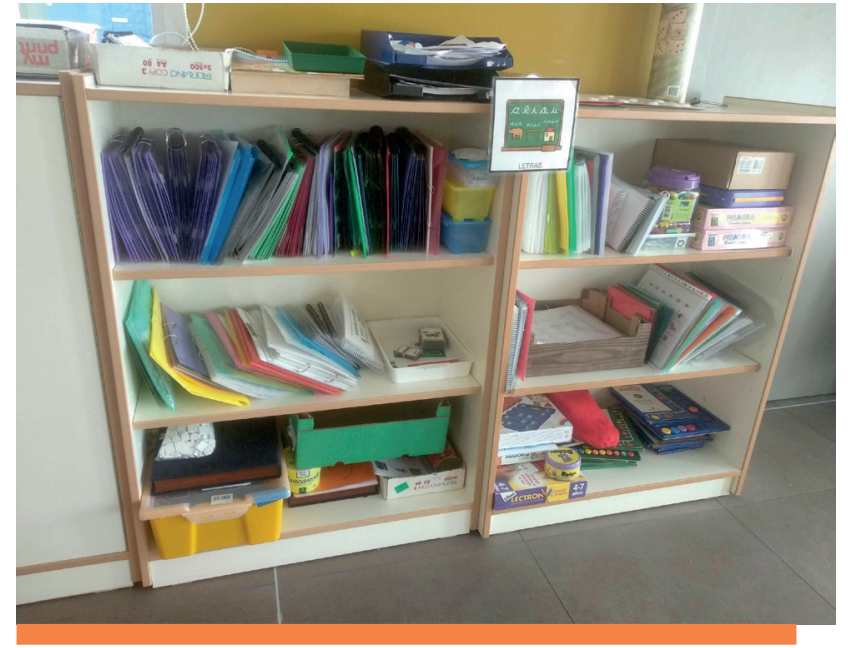

Imagen 9. Material de la estación de letras

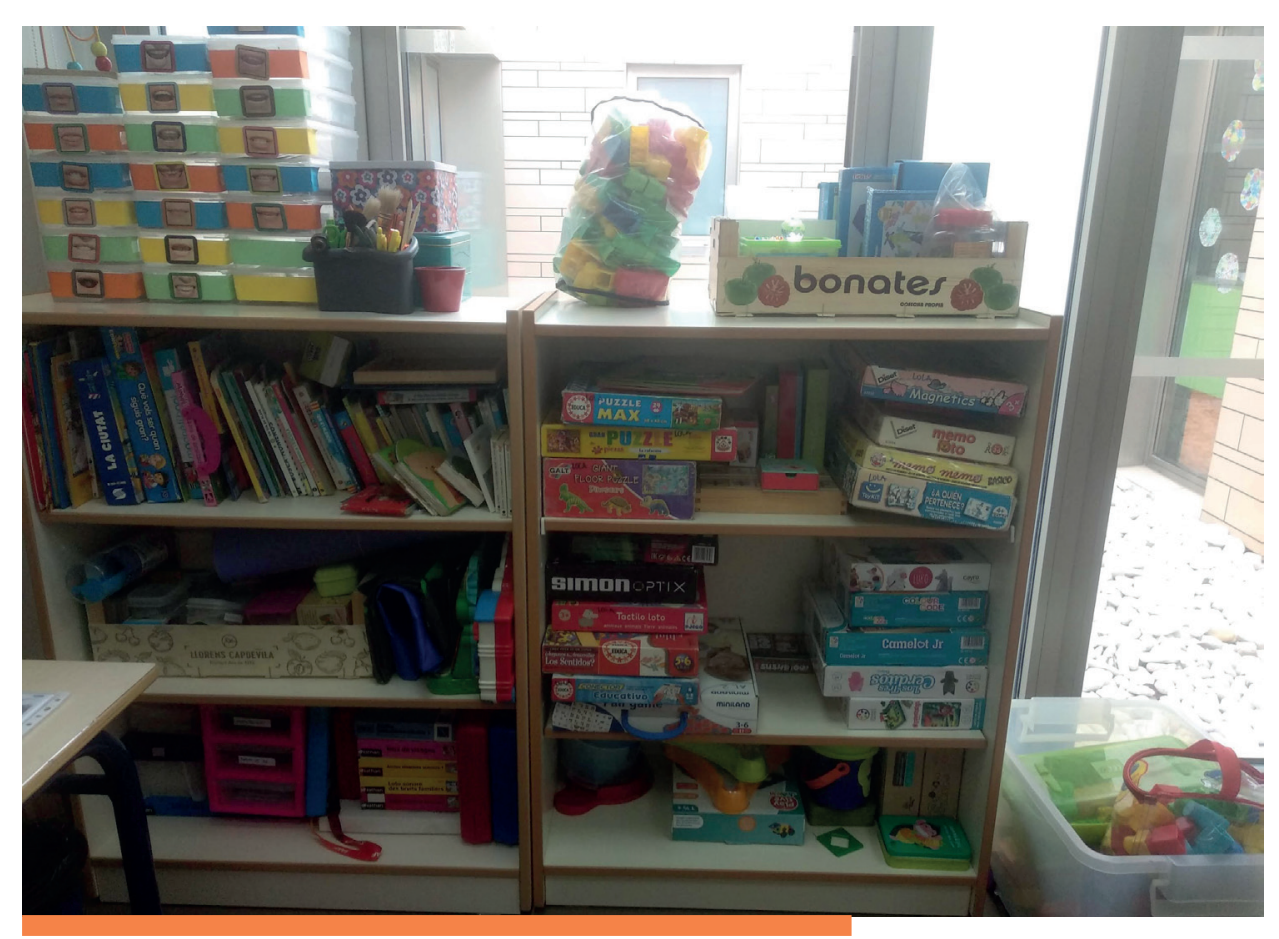

Imagen 10. Material de la estación de juegos de pensar 
E X P E R I E N C I A S

El aula está distribuida físicamente en diferentes zonas que se corresponden con las estaciones. Así nos es más fácil poder proporcionar ayuda en caso de que sea necesario. Con todo, pueden utilizar cualquiera de los espacios disponibles, incluso el patio interior.

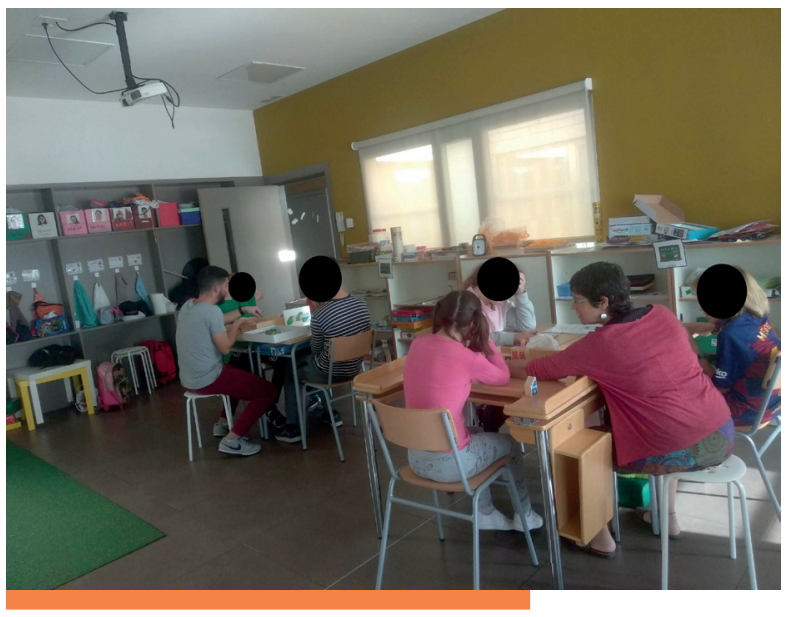

Imagen 11. Trabajo dentro del aula

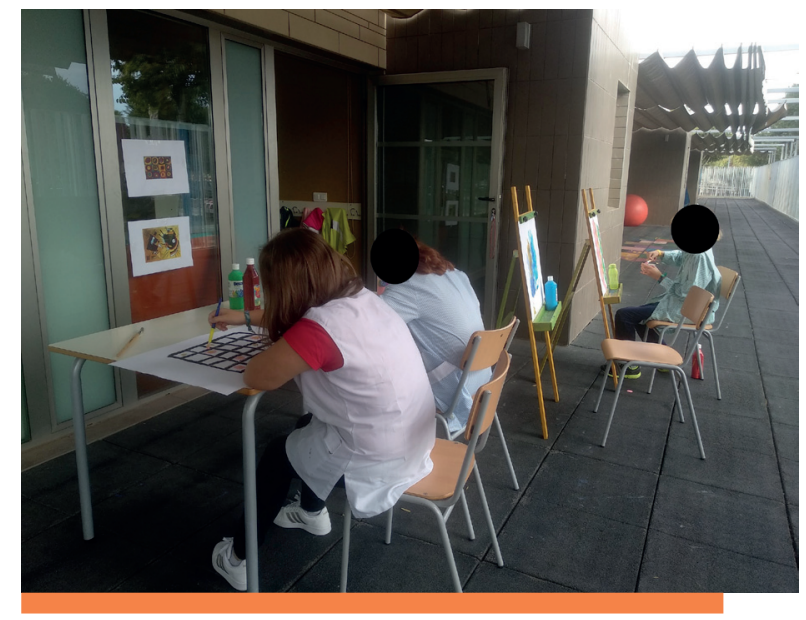

Imagen 12. Trabajo fuera del aula

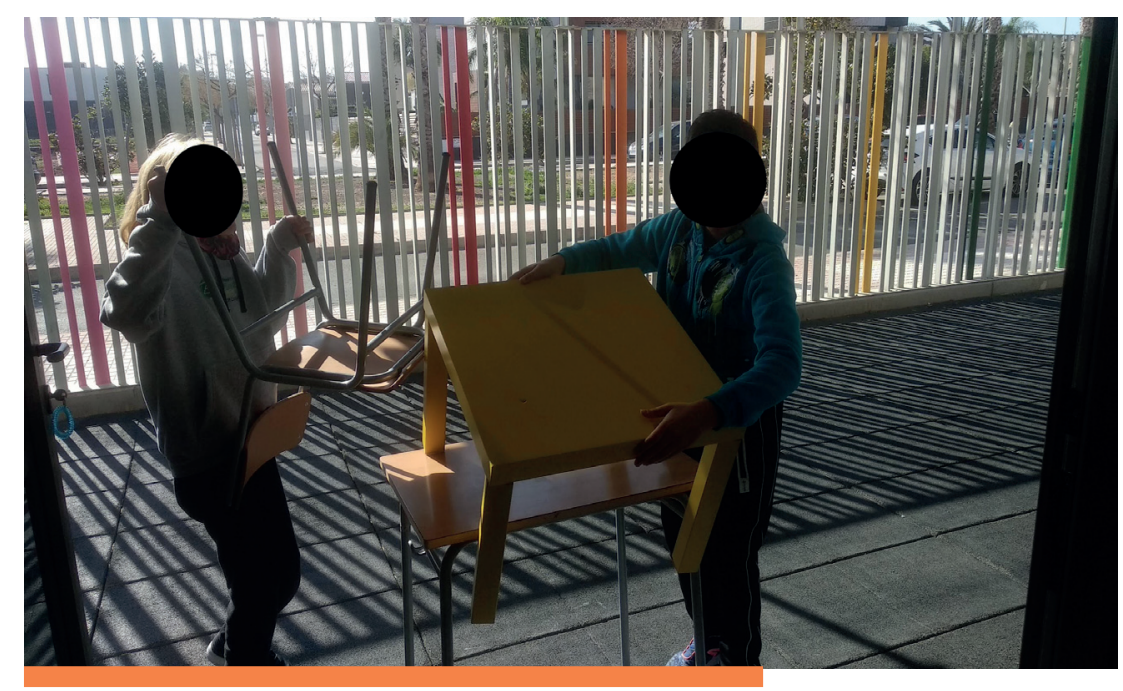

Imagen 13. Preparación del espacio de trabajo

La hoja de programación quincenal es nuestra guía para saber qué actividades tienen que trabajar durante estas dos semanas y con qué materiales debe hacerlo. Siempre tenemos diferentes propuestas para que puedan elegir lo que quieren hacer. Las propuestas se estructuran en dos niveles en función del mayor o menor nivel de supervisión o de acompañamiento que requieran. Hemos decidido planificar de esta manera porque en momentos donde un alumno determinado pueda necesitar más apoyo, ya sea porque tiene dificultades o porque hemos iniciado el trabajo de conceptos nuevos, nos encontramos en que el trabajo autónomo del resto es fundamental para poder proporcionar la atención necesaria. Por ejemplo, 3 alumnos han escogido trabajar en matemáticas y cada uno de ellos tiene un nivel diferente. Para evitar que dos de ellos esperen mientras explicamos la actividad al tercer alumno, les damos dos actividades que les motiven o que ya saben hacer sin apoyo y nos podemos dedicar a explicar tranquilamente. En el momento 
margenes

E X P E R I E N C I A S

en que acabamos la explicación, nos encargamos de uno de los otros dos alumnos, le damos el material y le hacemos la explicación de lo que va a hacer.

A continuación, se muestran unas fotografías sobre diversas actividades realizadas en las estaciones de aprendizaje. Tal como se puede observar la práctica totalidad de los materiales son manipulativos:

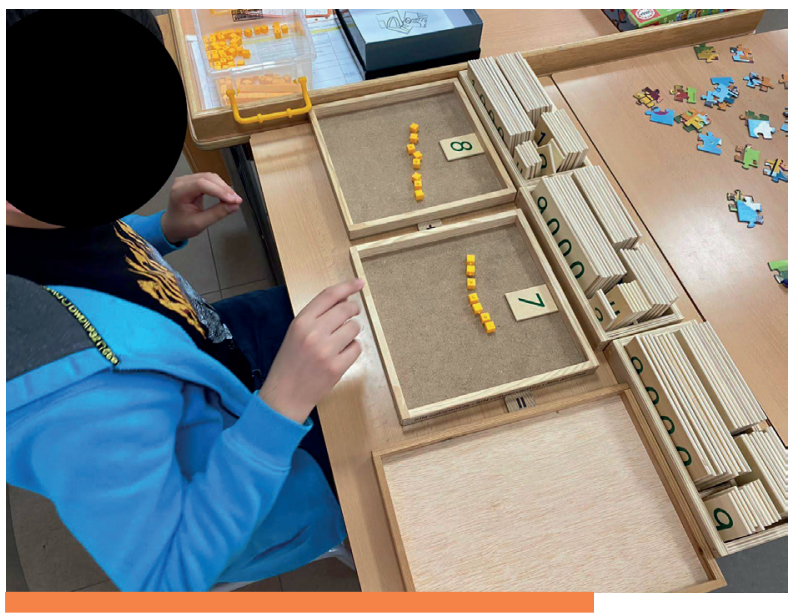

Imagen 14. Estación de los números: Resolvemos el enigma

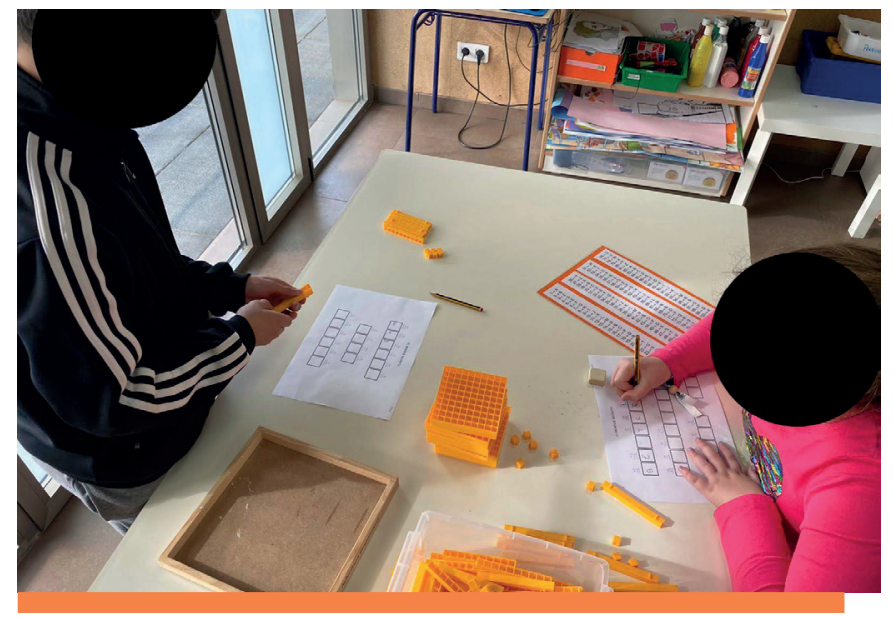

Imagen 15. Estación de los números: sumas

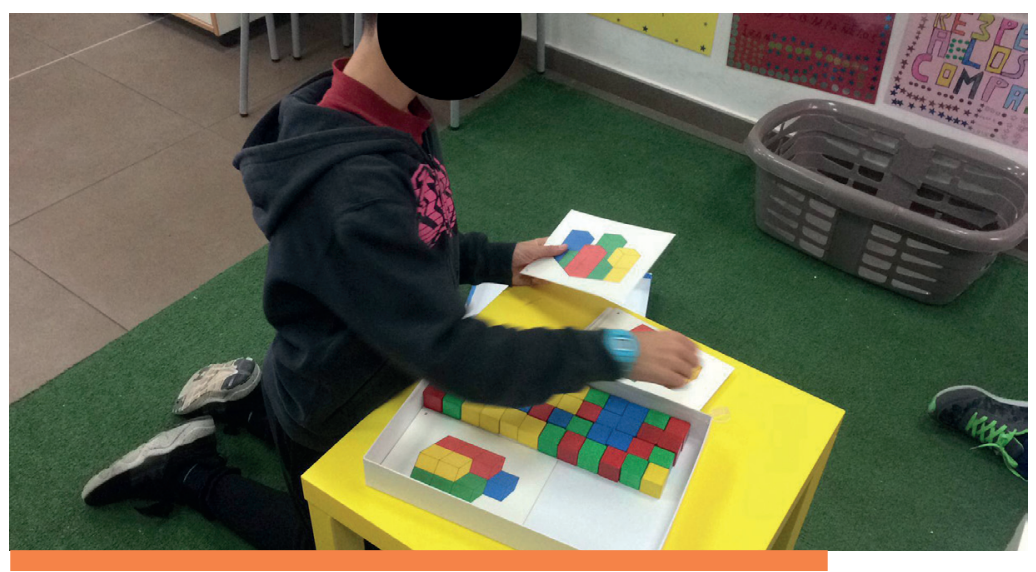

Imagen 16. Estación de los números: geometría

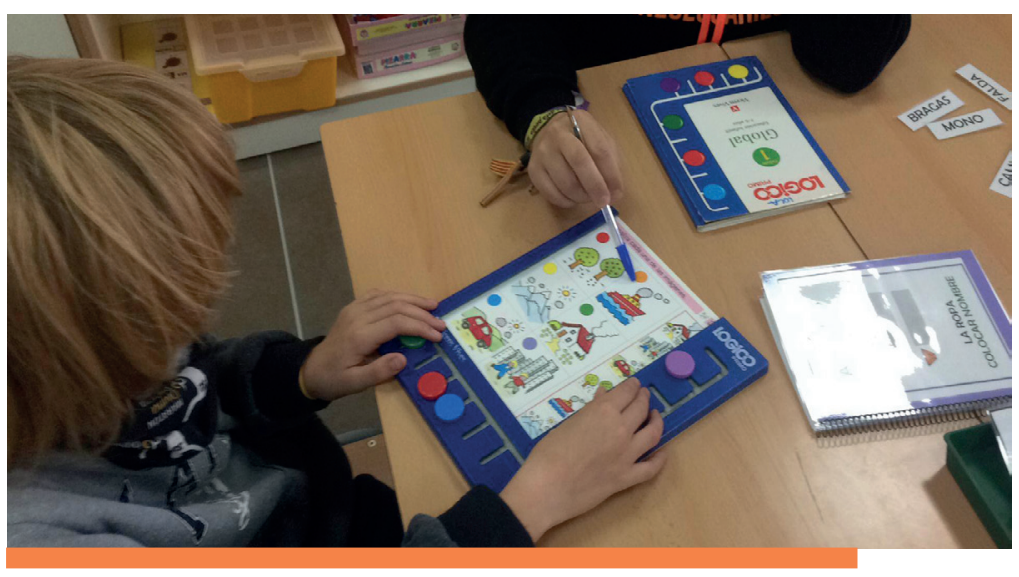

Imagen 18. Estación de las letras: razonamiento lógico

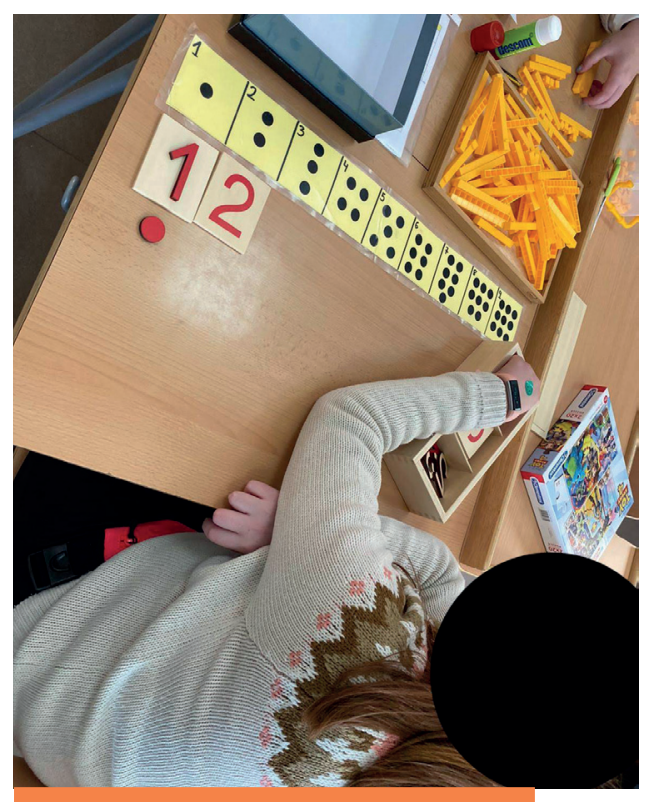

Imagen 17. Estación de los números: asociar número y cantidad 


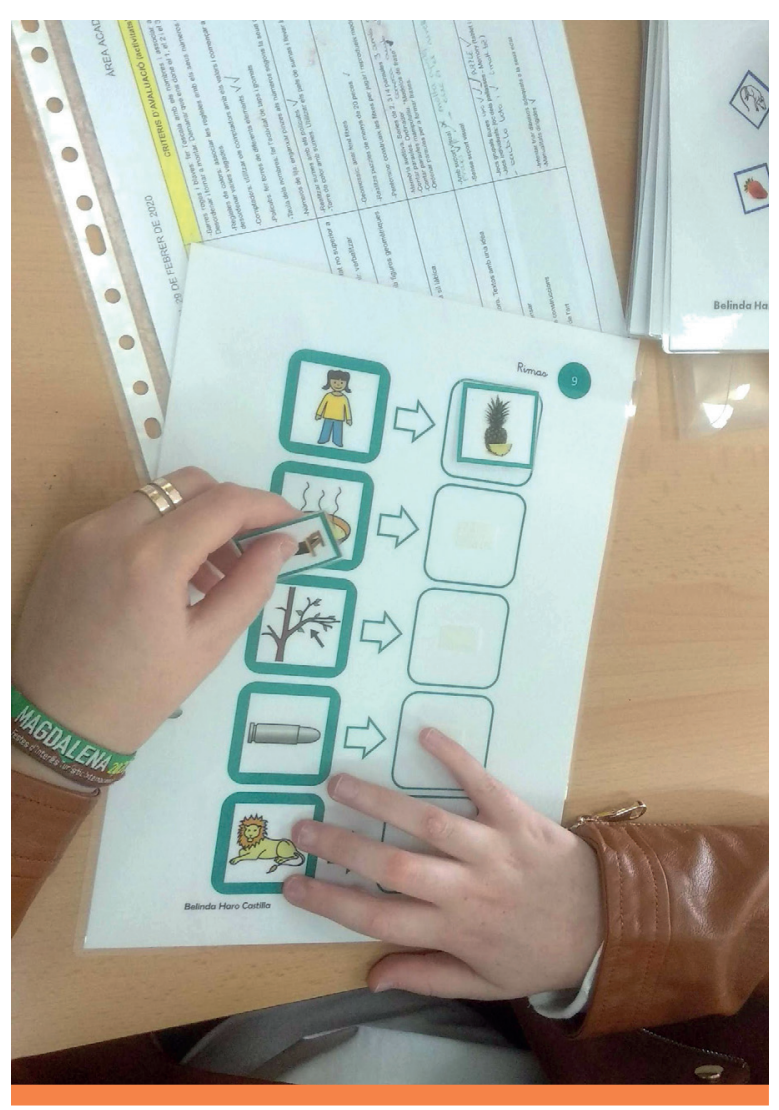

Imagen 19. Estación de las letras: conciencia fonológica (rimas)

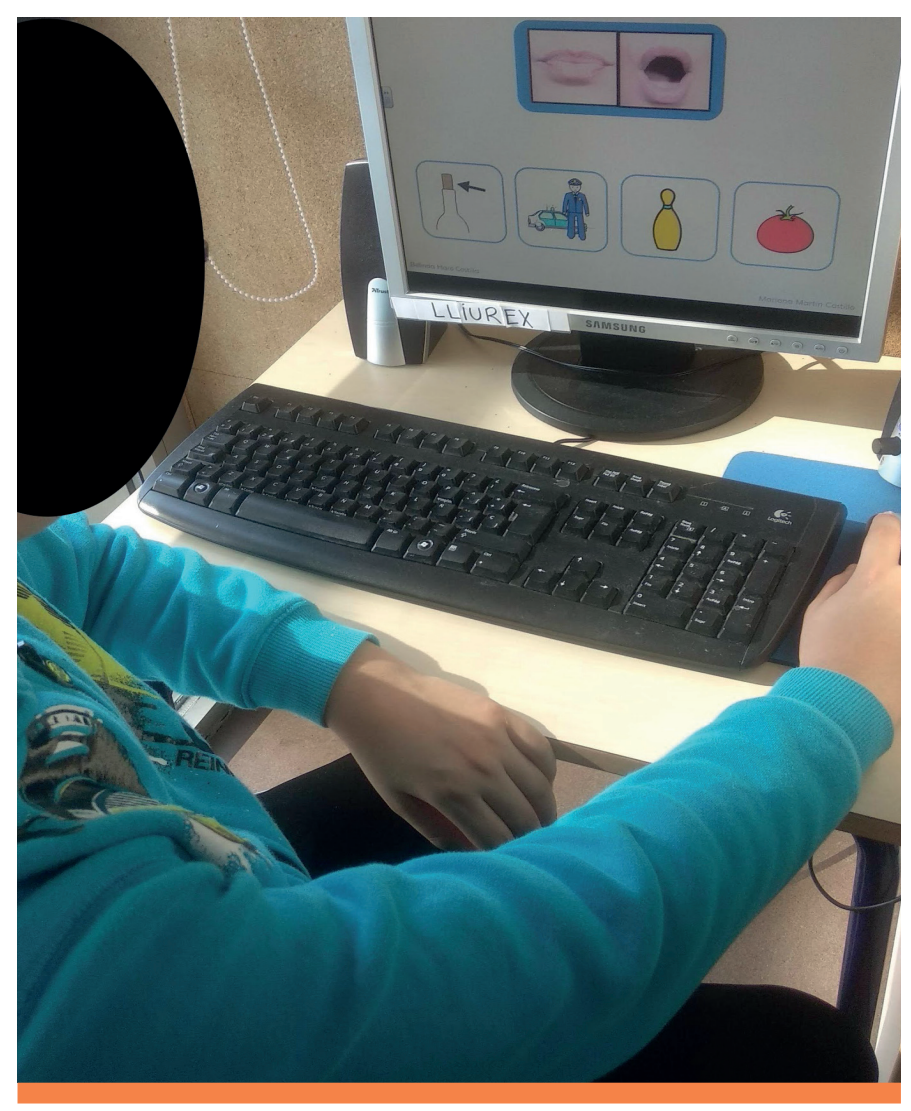

Imagen 20. Estación de las letras: conciencia fonológica (empieza por...)

\subsection{Juego del día}

Como se puede observar en el horario que se describió en el apartado de planificación temporal, después del patio nos encontramos con franjas de trabajo académico-funcional de una hora y media o de dos horas después de comer. Estas franjas de trabajo son excesivas para poder mantener la atención en las tareas propuestas. Inicialmente dividíamos el tiempo en dos y hacíamos un descanso de 5-10 minutos en los que ellos decidían qué querían hacer (normalmente, pedían ordenador), pero observamos que volver a trabajar se convertía en una fuente de conflictos. Por este motivo decidimos introducir las pausas activas.

En las sesiones de educación física el maestro les propone diferentes juegos que van aprendiendo y entrenando, algunos cooperativos, otros competitivos. Hemos recuperado estos juegos a través del juego del día. Cada día un alumno elige el juego al que jugaremos todos, y cuando ya llevamos en el aula unos 40 minutos de estaciones hacemos la pausa, que consiste en salir al patio a jugar a juegos motrices con normas y siguiendo unas instrucciones. Cuando se acaba este tiempo (5-10 minutos), volvemos a clase y seguimos con el trabajo.

Los resultados son muy positivos, el alumnado recupera la energía y la capacidad de atención y son capaces de seguir trabajando unos 30-35 minutos más. Además, de esta manera hemos conseguido que todos los días hagan actividad física y se muevan (hay que recordar que el índice de sobrepeso y de obesidad entre los alumnos de educación especial es superior al de la media). 


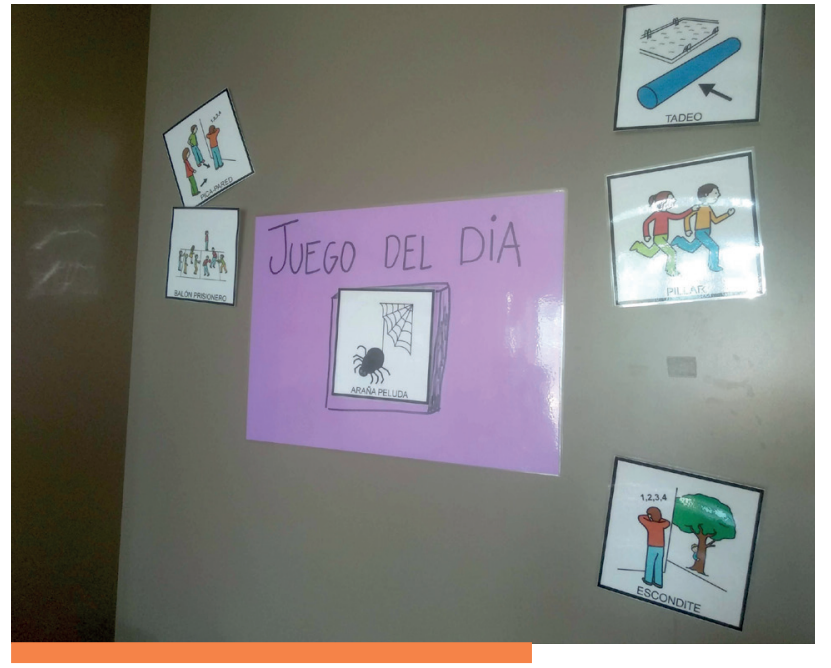

Imagen 21. Panel del juego del día

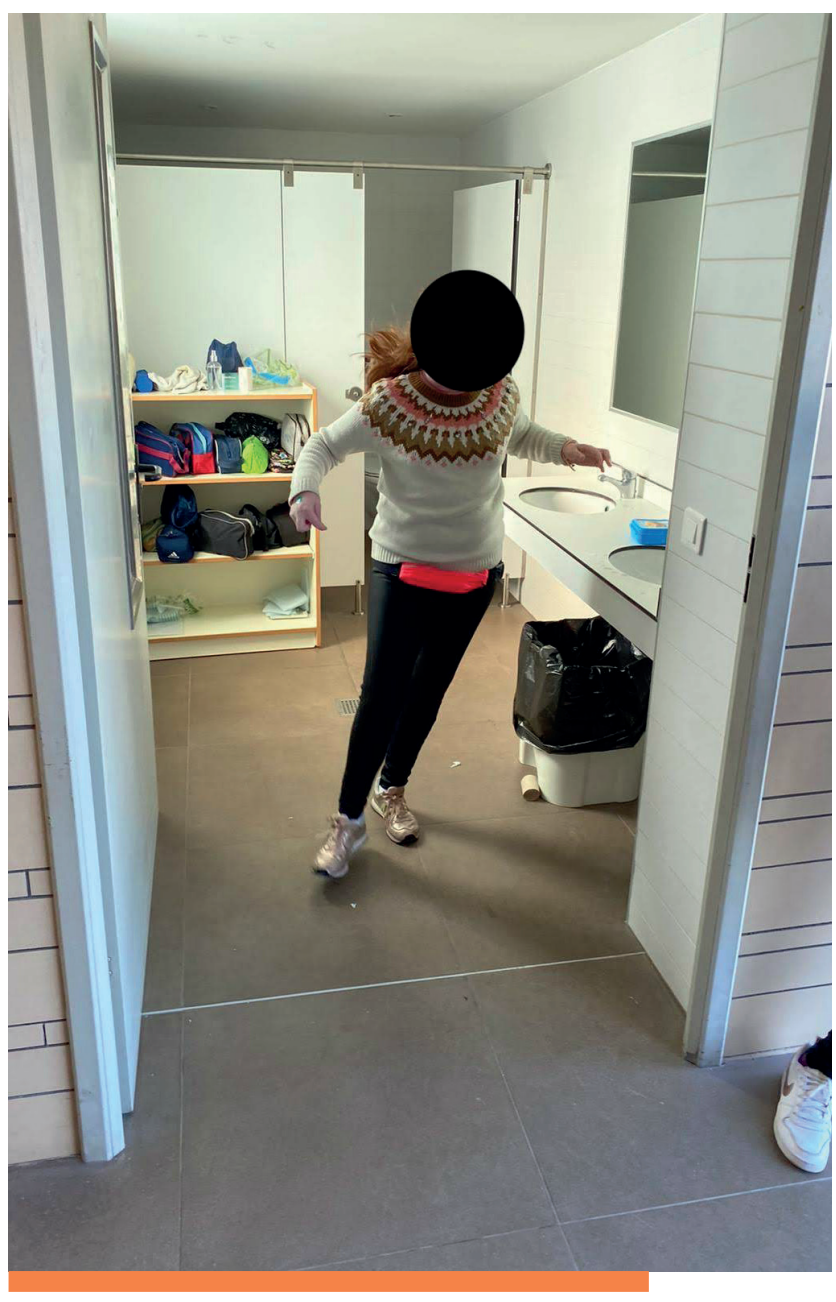

Imagen 23. Juego del día (escondite)

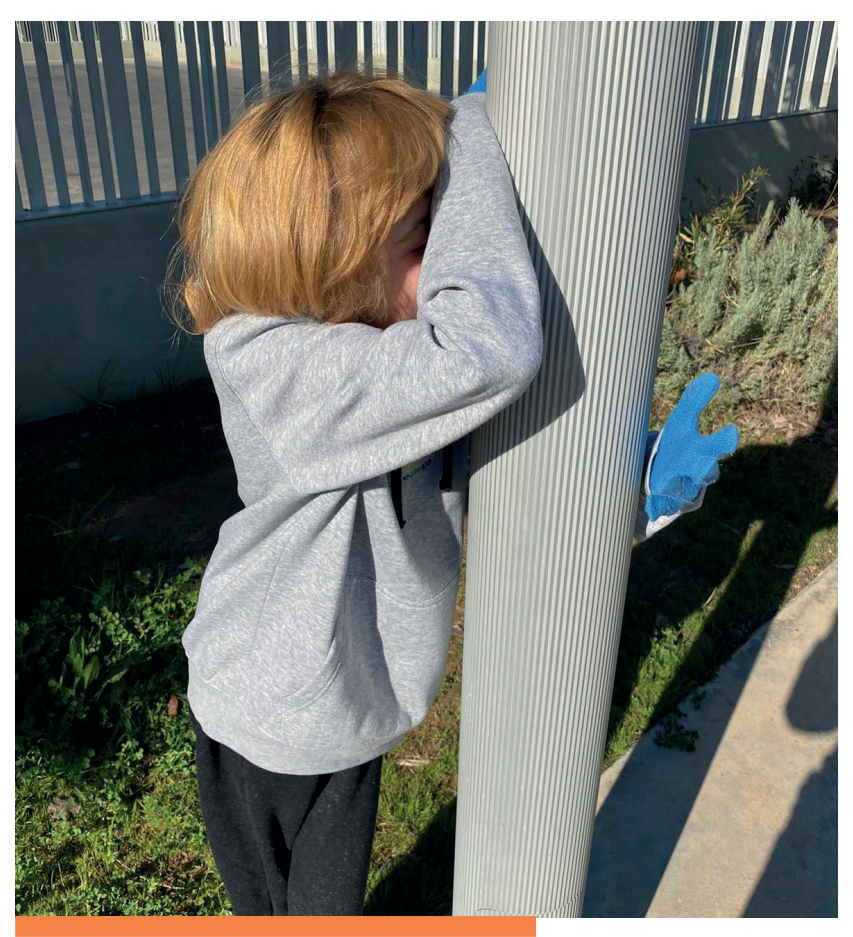

Imagen 22. Juego del día (escondite)

\subsection{Resumen de la semana: un espacio para la reflexión compartida}

Se trata de un momento de reflexión individual a partir de las actividades realizadas durante la semana, en el que valoramos especialmente toda la parte reflexiva más que el producto final.

A lo largo de toda la semana vamos haciendo fotografías de las actividades diarias que van realizando, ya sean de trabajo de aula o de momentos divertidos, curiosos u otras actividades de centro. Siempre pedimos permiso a los alumnos y les preguntamos si quieren la fotografía para su resumen semanal, y respetamos lo que nos dicen. Ellos saben que si no hay fotos, su resumen estará incompleto, lo razonamos con ellos y deciden si quieren o no la fotografía. De esta manera seguimos trabajando el respeto a sus decisiones y la autodeterminación.

Una vez tenemos las fotografías las imprimimos y se las damos recortadas. Podríamos hacer que fueran ellos los que las recortaran pero no perseguimos el objetivo de mejorar esta habilidad sino que priorizamos la parte de reflexión y de autoevaluación. 


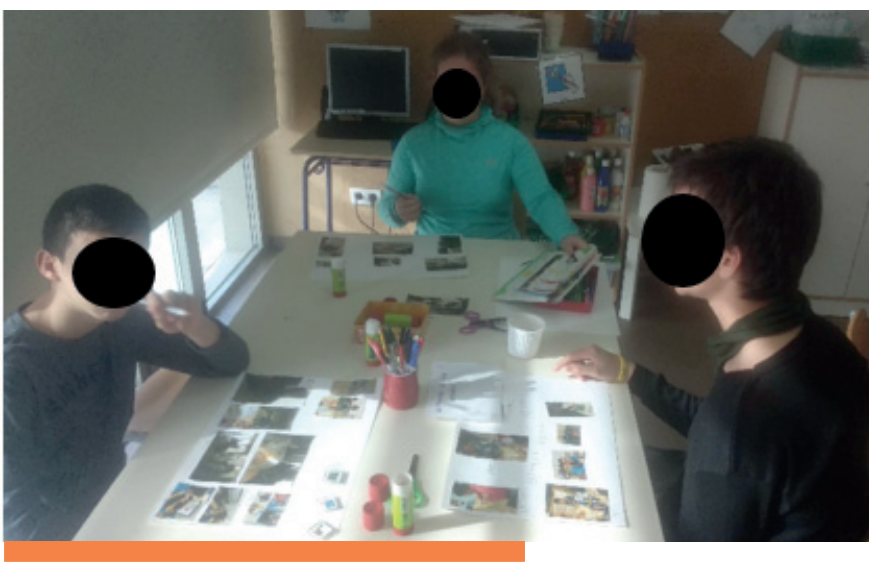

Imagen 24. Realización del resumen

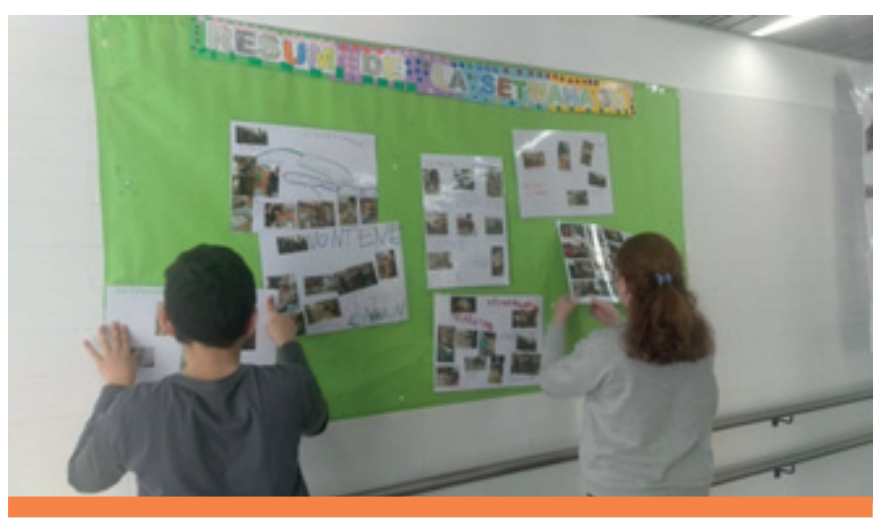

Imagen 25. Alumnos colgando los resúmenes en el mural
Buscan y preparan el material que necesitan (cartulina A3, colores, pegamento, tijeras...) y empiezan a escoger las fotografías que quieren poner en la cartulina y sobre las que quieren reflexionar o escribir algo. Las sobrantes las pegan detrás.

Una vez tienen las fotografías en la cartulina es cuando el papel de los docentes cobra sentido: debemos trabajar de manera individual la parte de reflexión y autoevaluación, haciendo énfasis y adaptándonos a las capacidades de comprensión de cada uno de nuestros alumnos. Es por ello que puede que con un alumno nos estemos centrando y valorando que ha trabajado solo, que cada día lo hace con mayor facilidad o que una actividad que ha hecho tres veces ya la sabe hacer autónomamente; y que con otra alumna estemos valorando la capacidad de esfuerzo, de superación o de autocontrol en momentos donde un mes antes hubiera abandonado la actividad.

Para reflejar esta autoevaluación deben completar las imágenes con una explicación. En este punto también queremos remarcar la personalización del trabajo según las características de nuestro alumnado:

- Alumna a la que la escritura le supone un gran esfuerzo y frustración, pero tiene un lenguaje oral muy elaborado y rico. En este caso ella dicta lo que quiere que le escribamos en el resumen, ya tendrá otras actividades donde trabajaremos su escritura.

- Alumno con un trastorno específico del lenguaje muy grave que le impide escribir con sentido pero que lo puede hacer de manera oral. En este caso él nos dicta y nosotros se lo escribimos en un papel. Esto le sirve como modelo para copiarlo debajo de las fotografías.

- Alumnos que tienen poca comprensión y hacen la reflexión a más bajo nivel. Copiamos o escribimos una o dos palabras debajo de cada fotografía; en estos casos sí nos centramos un poco más en la escritura de las palabras.

- Alumno sin lenguaje oral y escasa intención comunicativa, incapaz de realizar el resumen. Lo hacemos entre todos cuando terminamos nuestros resúmenes o lo realiza alguno de los alumnos que termina antes la actividad (y con este alumno ayudante trabajamos el concepto de ayuda y de trabajo cooperativo). 


\section{E X P E R I E N C I A S}

Por lo tanto, una misma actividad (el resumen), que persigue un mismo objetivo final (la autoevaluación), se concreta en tantos niveles como alumnos tenemos en el aula.

Una vez hemos realizado los resúmenes los plastificamos y los colgamos en el pasillo del centro durante una semana. De esta manera damos difusión a lo que hacen los alumnos dentro del Centro. Al pasar una semana, como hemos hecho los nuevos resúmenes, el alumnado se lo lleva a casa y la familia lo puede ver, así también son sabedores de la evolución de sus hijos e hijas y de las actividades que realizamos en el centro.

\subsection{Evaluación}

\begin{tabular}{|l|l|l|l|l|l|l|l|}
\hline \multirow{2}{*}{ INDICADOR DE LOGRO } & \multicolumn{7}{|c|}{ RÚBRICA DE EVALUACIÓN } \\
\cline { 2 - 8 } & $\begin{array}{c}\text { No realiza } \\
\text { la } \\
\text { actividad }\end{array}$ & $\begin{array}{c}\text { Realiza la } \\
\text { actividad con } \\
\text { modelado manual }\end{array}$ & $\begin{array}{c}\text { Realiza la } \\
\text { actividad con } \\
\text { ayuda visual y oral }\end{array}$ & $\begin{array}{c}\text { Realiza la } \\
\text { actividad con } \\
\text { ayuda oral }\end{array}$ & $\begin{array}{c}\text { Realiza la } \\
\text { actividad con } \\
\text { supervision } \\
\text { intermitente }\end{array}$ & $\begin{array}{c}\text { Realiza la actividad } \\
\text { de manera } \\
\text { autónoma con } \\
\text { errores }\end{array}$ & $\begin{array}{c}\text { Realiza la actividad } \\
\text { de manera } \\
\text { autónoma sin } \\
\text { errores }\end{array}$ \\
\hline 1 & & & & & & & \\
\hline 2 & & & & & & & \\
\hline 3 & & & & & & & \\
\hline 4 & & & & & & & \\
\hline 5 & & & & & & & \\
\hline OBSERVACIONES: & & & & & & \\
\hline
\end{tabular}

Imagen 26. Rúbrica de evaluación

Hacemos la evaluación quincenalmente y pasamos las observaciones a una rúbrica que valora especialmente el grado de apoyo que necesitan para trabajar, además de los contenidos alcanzados.

Cuando hemos conseguido que un alumno realice una actividad de manera autónoma - con o sin errores- o con supervisión intermitente (según el caso), pasamos al siguiente indicador de éxito de la ACIS.

Si no lo ha logrado buscamos causas: ¿el material no era el adecuado? ¿Le ha dedicado suficiente tiempo? ¿Ha estado cambiando de acompañante adulto cada día que hacía la actividad o ha habido una continuidad? ¿Estamos planteando tareas ajustadas al proceso cognitivo en el que se encuentra?

Para saber el nivel cognitivo situamos a cada alumno según la taxonomía de Bloom o de Simpson, y presentamos actividades ajustadas a su nivel de desarrollo.

Un elemento que nos permite hacer la evaluación es el resumen semanal. Gracias a él podemos hacer la valoración del producto final y también del proceso.

El feedback que nos proporcionan las familias también es muy importante, porque sin la generalización a otros contextos nuestra labor pierde el sentido. 
Como ya hemos comentado, el proyecto va creciendo a medida que lo vamos desarrollando. Estamos creando una rúbrica para evaluar el propio proyecto con indicadores objetivos, obviamente, pero también cualitativos ya que buscamos el cambio de actitudes y de destrezas personales en los alumnos.

\section{CONCLUSIONES}

Cuando llegamos al colegio hace 3 años teníamos claro que el lugar de cada uno de los alumnos era el colegio de su barrio, de su pueblo, y que si apostábamos por esa idea (que no es más que respetar la Convención sobre los Derechos de las Personas con Discapacidad), ese debía ser el camino. Pero también teníamos claro que el camino es largo, y que mientras trabajábamos para lograr esa meta nuestros alumnos se merecían una educación de calidad y tan inclusiva y respetuosa como nos fuera posible.

Sabemos que los centros de educación especial son segregadores y generadores de injusticias, y que muchas personas no conciben que dentro de ellos se puedan desarrollar prácticas inclusivas por esa premisa inicial. Consideramos que no es del todo cierto. Los centros específicos acostumbran a perpetuar las prácticas tradicionales que también están presentes en los centros ordinarios, y con nuestro proyecto hemos intentado ofrecer una manera de organizar el aula y una metodología que ponen a los jóvenes en el centro, otorgándoles el protagonismo que les corresponde. Para ello hemos investigado, hemos visitado otros centros, compartido con compañeros de diferentes niveles educativos, y nos hemos formado para disponer de herramientas para el cambio.

Sin el cambio de mirada inicial nada de todo esto hubiera sido posible. Además, una vez inicias el camino es imposible volver atrás y recuperar las prácticas educativas que hacías antes sin traicionarte a ti mismo/a. Y esta es la base de todo lo que hemos ido creando. Ha sido un viaje en el que ante cada reto nos planteábamos preguntas, ante cada idea que nos transmitía un compañero, que recogíamos en una formación, cualquier cosa nos servía para cuestionar lo que estábamos haciendo e intentar mejorar.

Nuestro papel ha sido proporcionarles herramientas para que sean los verdaderos protagonistas de su vida, ofrecerles apoyos para que se empoderen y reclamen sus derechos, haciendo valer su opinión y sus decisiones. Ese es el espíritu de todo lo que hacemos, a pesar de que por desgracia no es lo que se acostumbran a encontrar los niños y los jóvenes en las escuelas y en los institutos, y todavía menos el alumnado de centro de educación especial.

Tenemos claro que este proyecto nos ha sido útil este año y con el alumnado que tenemos. Pero también tenemos claro que el proyecto tiene que estar al servicio de los alumnos, y no al revés. Este curso que comienza nos va a brindar la oportunidad de empezar de nuevo: nuevo centro, nuevos alumnos, nuevas metodologías, nuevos equipos educativos. Y esta es la grandeza de la educación, está viva, en constante cambio. No podemos estancarnos en lo que hemos hecho un año porque haya ofrecido resultados interesantes, cada nuevo alumno es una oportunidad de mejorar nuestra práctica, y así lo entendemos nosotros. 


\section{REFERENCIAS}

Alba, C; Sánchez Serrano, J.M. y Zubillaga, A. (2011). Diseño Universal para el Aprendizaje (DUA) Pautas para su introducción en el currículo. Informe. España: Autores. Recuperado de https://bit.ly/3jaSlvT

Arnaiz, P. (2003). Educación inclusiva: una escuela para todos. Editorial Aljibe.

Bilbatua, M. y Egizabal, D. (2010). Las rúbricas en la reflexión sobre el trabajo en equipo., en K. Bujan, (coord.): Seminario internacional las rúbricas de evaluación en el desempeño de competencias: ámbitos de investigación y docencia. Universidad del País Vasco, 17-18 de junio.

Booth, T. y Ainscow, M. (2002). Guía para la evaluación y mejora de la educación inclusiva. Desarrollando el aprendizaje y la participación en las escuelas. España: CSIE y Consorcio Universitario para la Educación Inclusiva. Recuperado de https://bit.ly/3jitkYj

Cast (2008). Diseño universal del aprendizaje Versión 1.O. Wakefield, MA: Author. Recuperado de https:// bit.ly/2EaQQix

Catarralá, A.; Mata, G. y Crespo, V. (2017). Planificación centrada en la persona: planificando por adelantado el futuro deseado. Materiales de apoyo para facilitar procesos de PCP con personas con discapacidad intelectual y edad avanzada. Fundación San Francisco de Borja para personas con discapacidad intelectual. Centro San Rafael. Plena inclusión España. Recuperado de https://bit.ly/2Jkfq2I

Collicott, J. (2002). Posar en pràctica l'ensenyament multinivell: estratègies per als Mestres. Suports: revista catalana d'educació especial i atenció a la diversitat, 4(1), 87-100. Recuperado de https://bit. ly/34tTWsr

Diíaz Barriga, F. (2005). Enseñanza situada: Viínculo entre la escuela y la vida. McGraw Hill.

Huguet, T. (2006). Aprender juntos en el aula. Graó.

O’Brian, J. (1987). A guide to life-style planning: Using the activities Catalog to integrate services and natural systems. En B. Wilcox y G.T. Bellamy (Eds). Comprehensive guide to the Activities Catalog: An alternative curriculum for youth an adults with severe disabilities (pp. 175-189). Paul H. Brookes Publishing Co.

Red Territorial de educación infantil de Cataluña (2011). Documentar la vida de los niños y las niñas en la escuela: 28 (Temas de infancia). Rosa Sensat. Octaedro.

Sandoval, M.; López, M.L.; Miquel, E.; Durán, D.; Giné, C. y Echeita, G. (2002): Index for inclusión. Una guía para la evaluación y mejora de la educación inclusiva. Contextos educativos, 5, p.221-238. doi: https://doi.org/10.18172/con.514

Schalock, R. y Verdugo, M.A. (2007): El concepto de calidad de vida en los servicios de Apoyo para personas con discapacidad intelectual. Revista española sobre discapacidad intelectual, 38(4), 224, 2136. Recuperado de https://bit.ly/31mBHDy

Stainback (2001): L'educació inclusiva: definición, context i motius. Suports, 5(1), 18-20. Recuperado de https://bit.ly/3fQXxV1

Schulz, B. y Turnbull, P. (1984). Mginstreamlng Handicapped Students. Allyn \& Bacon, Inc.

Tomlinson, C. (2001). El aula diversificada. Octaedro 
Decreto 104/2018, de 27 de julio, del Consejo, por el que se desarrollan los principios de equidad y de inclusión en el sistema educativo valenciano. Diario Oficial de la Generalidad Valenciana, 8356, de 7 de agosto de 2018, 33355-33381. Recuperado de https://bit.ly/3mtFneQ

Decreto 108/2014, de 4 de julio, del Consejo, por el que se establece el currículo y desarrolla la ordenación general de la educación primaria en la Comunidad Valenciana. Diario Oficial de la Generalidad Valenciana, 7311, de 7 de julio de 2014, 16325-16694. Recuperado de https://bit.ly/2JuK8pw

Orden 20/2019, de 30 de abril, de la Consejería de Educación, Investigación, Cultura y Deporte, por la que se regula la organización de la respuesta educativa para la inclusión del alumnado en los centros docentes sostenidos con fondos públicos del sistema educativo valenciano. Diario Oficial de la Generalidad Valenciana, 8540, de 3 de mayo de 2019, 20853-20897. Recuperado de https://bit. ly/2VjrhR8

Resolución de 24 de julio de 2019, dela Secretaría Autonómica de Educacióny Formación Profesional, por la que se dictan instrucciones para la aplicación de algunos de los principales procedimientos previstos en la Orden 20/2019, de 30 de abril, de la Consejería de Educación, Investigación, Cultura y Deporte, por la que se regula la organización de la respuesta educativa para la inclusión del alumnado en los centros docentes sostenidos con fondos públicos del sistema educativo valenciano, y se publican los formularios referidos a la evaluación sociopsicopedagógica, el informe sociopsicopedagógico, el plan de actuación personalizado (PAP) y el dictamen para la escolarización. Diario Oficial de la Generalidad Valenciana, 8602, de 30 de julio de 2019, 35648-35666. Recuperado de https://bit. $1 \mathrm{y} / 36 \mathrm{p} 3 \mathrm{u} 8 \mathrm{R}$

Resolución de 24 de julio de 2019, de la Secretaría Autonómica de Educación y Formación Profesional, por la que se dictan instrucciones para la aplicación de los procedimientos para la solicitud y desarrollo de la atención educativa al alumnado hospitalizado o convaleciente en su domicilio por enfermedad, previstos en la Orden 20/2019, de 30 de abril, de la Consejería de Educación, Investigación, Cultura y Deporte, por la que se regula la organización de la respuesta educativa para la inclusión del alumnado en los centros docentes sostenidos con fondos públicos del sistema educativo valenciano. Diario Oficial de la Generalidad Valenciana, 8602, de 30 de julio de 2019, 3566735690. Recuperado de https://bit.ly/3fslAmG 